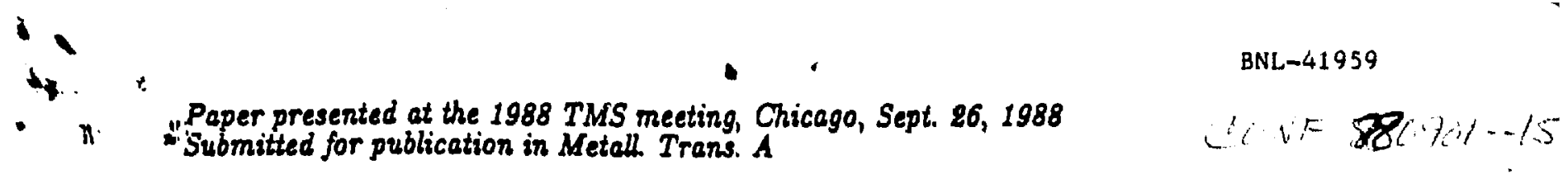

BNL -41959

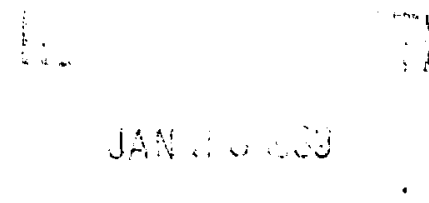

DE89 005766

\title{
POSITRON SPECTROSCOPY FOR MATERIALS CHARACTERIZATION
}

\author{
Peter J. Schults \\ Department of Physics, The University of Western Onterio \\ London, Ontario N6A 9K7, CANADA \\ C.L. Snead, Jr. \\ Brookhaven National Laboratory \\ Upton, NY 11979, U.S.A.
}

\section{ABSTRACT}

One of the more active areas of research on materials involves the observation and characterization of defects. The discovery of positron localization in vacancy-type defects in solids in the 1960's initiated a vast number of experimental and theoretical investigations which continue to this day. Traditional position annihilation spectroscopic techniques, including lifetime studies, angular correlation, and Doppler broadening of annihilation radiation, are still being applied to new problems in the bulk properties of simple metals and their alloys. In addition new techniques based on tunable sources of monoenergetic positron beams have, in the lest 5 years, expanded the horizons to studies of surfaces, thin films, and interfaces. In the present paper we briefly review these experimental techniques, illustrating with some of the important accomplishments of the field.

\section{DISCLAIMER}

This report was prepared as an account of work sponsored by an asency of the United States Government. Neither the United States Government nor any agency thereof, nor any of their emptoyees, makes any warranty, express or implied, or assumes any legal liability or responsibility for the accuracy, completeness, or usefulness of any information, apparatus, product, or process discloeed, or represents that its use would not infringe privately owned rights. Reference herein to any specific commercial product, process, or service by trade name, trademark, menufacturer, or otherwise does not necessurily constitute or imply its endorsement, recommendation, or favoring by the United States Government or any afency thereof. The views and opinions of authors expreseed herein do not necessurily state or reflect thowe of the Uniled States Government or any agency thereof. 


\section{INTRODUCTION}

Positrons have been used to study solids in various ways for more than 30 gears now. As the antimatter equivalent of the electron, the positron turns out to be an extremely sensitive probe of both structural and electronic properties of the solid lattice. In addition, the intensities typically required for most useful experiments are sufficiently low that probe-induced radiation damage is negligibly small. The benefits of this high sensitivity are in part contrasted by the fact that the positron-solid interaction is often too complicated to describe completely, and many of the experiments done necessarily result in only semi-quantitriive conclusions or interpretation. Nevertheless, the past 3 decades have seen tremendous advances in positron/solid-state research; not only in the development of new techniques and applications, but also in the understanding of some of the fundamental aspects of positron-solid interactions.

In the present paper we will brielly discuss the most common experimental techniques, and review some of their applications to studies of materials (with particular emphasis on metals). One of the more distinguished areas of positron research is the study of defects, primarily because there are few other nondestructive techniques that can compete with the sensitivity and selectivity of positrons. We will therefore emphasize this work in the following discussion. We will also separate the text roughly into two halves. The first part will feature a general discussion of positron interactions with solids, and the so-called "bulk" techniques which have evolved to study these. The second part of the text will focus on the relatively new technique of producing monoenergetic positron beams, and a few examples of studies similar to those described in the first part. More detailed descriptions of the 
experimental techniques and more diverse accounts of the different types of research can be found in the books and reviews by Hautojärvi (1979), Brandt and Dupasquier (1983), Jain et al. (1985) and Schultz and Lynn (1988).

\section{BULK MATERIAL STUDIES WTTH POSITRONS}

The traditional experiment with positrons uses a relatively weak positron emitting radioisotope (e.g., 10's of $\mu \mathrm{Ci}$ of ${ }^{22 \mathrm{Na}}$ ) located near the sample to be studied. Positrons are emitted from the source with the usual $\beta$ energy distribution that is continuous from zero up to the endpoint energy (which is $-546 \mathrm{keV}$ for ${ }^{22 \mathrm{Na}}$; Massoumi et al., 1988). This range of energies make these truly "bulk" measurements. Positrons that enter the sample quickly thermalize $\left(t<10^{-11} \mathrm{sec}\right)$ at depths that are large (i.e., tens of $\mu \mathrm{m}$; Hansen et al., 1982) compared with the mean diffusion length (of order $0.1 \mu \mathrm{m}$; Bergersen et al., 1974). Freely diffusing positrons have a mean lifetime before annihilation with an electron that is on the order of $10^{-10} \mathrm{~s}$ in solids, which means that for most experiments there is rarely more than one positron in the sample at any given time. Annihilation of positrons before they reach near-thermal energies was discussed by Heitler (1947), and it accounts for at most a few percent of the total, so the positron lifetime and the center-oi-mass (c.m.) momentum of the annihilating pair are determined primarily by the electron distribution which the positron wave function samples.

The free-position wave function is represented by a Bloch function, with a deBroglie wavelength given by 


$$
\lambda_{\text {th }}=\frac{2 \pi \hbar}{\left(3 m k_{B} T\right)^{1 / 2}} \sim(62 \AA)\left(\frac{300}{T}\right)^{1 / 2} .
$$

If there is an open-volume defect in a metal lattice, the positron wave function can condense into the potential minimum with high efficiency (vacancy trapping rates $-10^{15} \mathrm{sec}^{-1}$ in metals). The dramatic change in the wave function from a freely diffusing to a vacancy-localized state was calculated by Puska and Nieminen (1983), and is illustrated in Fig. 1. In the defect the positron overlaps with an electron distribution that is of lower density, which increases its lifetime as much as $45 \%$, and is of lower average momentum (due to less overlap with core electrons). These changes are easily observed using one of the 3 most common techniques illustrated in Fig. 2, and described below.

Angular correlation of annibilation radiation (ACAR; Fig. 2(a)) is based on the fact that the 2 annihilation $\gamma$ rays deviate from collinearity because of the finite $\mathrm{c} . \mathrm{m}$. momentum discussed above. The momentum distribution is measured in one dimension using long-slit detectors, or in two dimensions using position-sensitive detectors. The spread in momentum also results in a Doppler shift (Fig. 2(b)) of the $511 \mathrm{keV} \gamma \mathrm{ray}$, which is measured using a solid-state detector and can be parametrized by" the normalized area of a central portion of the peak, called the "S parameter" (defined in Fig. 3). The width of the annihilation line can also be (more or less equivalently) parametrized using the "W parameter", which is the normalized area in 2 symmetrically spaced regions located in the "wings" of the peak. The third technique represented in Fig. 2(c) is the measurement of positron lifetime, which is the time difference between a fiducial $\gamma$ ray emitted from the source $\left({ }^{-1.275 ~ M e V ~ f o r ~}{ }^{22 \mathrm{Na})}\right.$ when the positron is ejected, and the annihilation $\gamma$ ray. Several lifetimes can in some 
cases be deconvolved from the experimental data. Other experimental methods are used in positron studies of solids, but the above are by far the most common (see, e.g., Hautojärvi, 1979).

It is generally true, as suggested by Fig. 1, that as the size of the open-volume defect increases, the characteristics of annihilation will also be influenced. This is manifested in (1) a further increase in the lifetime of positrons annibilating from the trap, (2) a narrowing of the ACAR spectrum, and (3) a narrowing of the Doppler broadening spectrum (larger S-parameter) as the size of the defect increases. We look first at this effect in cases where cavities can nucleate and/or grow owing to the migration of point defects.

Hautojärvi et al. (1977) and Jena et al. (1977) calculated the lifetimes to be expected from annibilation from various-sized voids by first calculating the electron density inside the voids. Figure 4 shows their results for small voids in Al and Mo. The differences in the two curves at small void radii reflect different lifetimes for single vacancies in the two metals. Note, however, that for larger voids ( $10 \AA$ and larger) the lifetime approaches a saturation value that is essentially independent of the metal. This is a general feature of lifetimes in voids in metals. Hautojärvi et al. (1977), using their calculations and the lifetime data on voids in molybdenum taken from Eldrup et al. (1976), related the lifetimes to the number of vacancies in the respective voids. This is shown in Fig. 5. The reader should note that the precision of the lifetime determination is typically the size of the plotted point. Thus, the measured change in lifetime can provide a very sensitive determination of the change in void sizes over a range from single-vacancy size up to voids of $\sim 10 \AA$. This makes positron spectroscopy a powerful tool in nucleation and growth studies of voids in the range where the 
traditional technique, transmission electron microscopy (TEM), is insensitive.

Lifetime and Doppler-broadening studies have contributed significantly to the understanding of roids (generalized to cavities) in irradiated materials (see, for instance, Jain et al., 1985). Herein we present only a few examples. Thrane and Evans (1977) using lifetime measurements investigated Mo aśter ambient-temperature irradiations and subsequent annealing following both neutron and electron irradiation. Their results are shown in Fig. 6. The as-irradiated results point out one immediate difference in the initial defect state between the two irradiations. The defect lifetime for the electron-irradiated specimen is indicative of annitilation from single-vacancy traps. The higher lifetime for the neutron-irradiated specimen, however, shows that annihilations are taking place from traps involving more than one vacancy (vacancy clusters). This is readily in keeping with our understanding of the primary knock $\rightarrow$ on energy transfer and damage-production mechanisms of the electron and neutron. Based upon the results of Figs. 4 and 5 one estimates that for the neutron-irradiated specimen the average defect radius after irradiation is between 2 and $3 \AA$ corresponding to an average defect comprised of $\sim 4$ vacancies.

Isochronal annealing of both specimens up to $4400{ }^{\circ} \mathrm{C}$ shows agglomeration of the migrating single vacancies (and presumably small clusters) to the point where the average void size is $>10 \AA$ and the lifetime is "saturated" at 450 ps. An interesting feature, however, develops upon further annealing above $400^{\circ} \mathrm{C}$. The lifetime increases above the "saturation" void value. This increase is attributed to the introduction of nitrogen gas into the specimens during the anneal and the subsequent accretion of the nitrogen into the voids. Annealing of similar specimens in vacuum produced no such anomalous increases in lifetime above the void lifetime value, thereby confirming the 
nitrogen/void interaction. Although the highlight here is the utility of the positron parameters to follow void nucleation and growth, the gas-in-metal sensitivity is also seen and will be, itself, discussed later.

One of the major concerns in using metals in radiation environments such as for structural elements in fission or fusion reactors is their propensity to swell due to the evolving microstructure induced by the irradiation. The chief problems in the microstructure are the cavities (roids, voids with internal gas, and bubbles). It has been, therefore, imperative that the swelling behavior as a function of temperature for candidate materials be understood so as to project swelling impact at the proposed operating temperatures of the metals. Figure 7 shows a plot of $I_{2}$ (the intensity of the annihilation component associated with voids, which is related to the total volume of the voids present) versus the temperature of the neutron irradiation (Snead et al., 1982). The "swelling curves", and in particular the peak swelling, for both Mo and the alloy Mo-1/2 at.\% are well defined. Measurable swelling is found over a range $400-1400^{\circ} \mathrm{C}$ for $\mathrm{Mo}$, although the Mo alloy shows somewhat less total swelling and a shift of the peak to a lower temperature.

As indicated earlier, where small cavities are present positron spectroscopy complements TEM. In the above study of Snead et al. (1982) it was shown that information on the swelling behavior during irradiation could also be obtained from the Doppler-broadening measurements done concurrently with the lifetime determinations. Figure 8 shows an S-parameter plot for Mo similar to that of Fig. 7. The differences between the (round) plotted points for repeated measurements on specimens irradiated at the same temperature is representative of the reproducibility of the positron results. Note in comparison the large error bars on the TEM value for the highest (and most 
resolvable) damage level, and also the inability of TEM to resolve any swelling at the lowest and highest temperatures. Positron spectroscopy is about a factor of 10 more precise in establishing the roid swelling characteristics as a function of temperature and can do so for dose levels that are at least two orders of magnitude iower than those needed for TEM determinations.

In one early study of bubble formation using positrons, Snead et al. (1975 and 1977) investigated aluminum injected with He to $0.6 \mathrm{appm}$ at room temperature and subsequently annealed. Two helium migration stages. at $\sim 150^{\circ} \mathrm{C}$ and $550^{\circ} \mathrm{C}$ were identified. An increasing trap lifetime traced the nuclesition and growth of helium bubbles up to $500^{\circ} \mathrm{C}$ where the concentration reduction with increasing bubble size caused the lifetime to regress back toward pure Al (see Fig. 9). From the largest lifetime achieved, $\sim 300 \mathrm{psec}$, one estimates the average "bubble" size at $500^{\circ} \mathrm{C}$ to be less than $10 \AA$. The TEM performed at 300,400 , and $500^{\circ} \mathrm{C}$ revealed bubbles at $500{ }^{\circ} \mathrm{C}$ only, but they were very small and of very low concentration. TEM done on the $625^{\circ} \mathrm{C}$-annealed specimen produced a clearly resolved population of bubbles with an average size of $900 \AA$, but with a concentration of $5 \times 10^{11} / \mathrm{cm}^{3}$. The range in observed cavity sizes was from 200 to $2300 \AA$. A rough estimate indicates that all $(0.6 \mathrm{appm})$ of the He went to bubbles, not to the specimen surface.

There has been a great deal of work using positron techniques to investigate other interstitial-impurity interactions with radiation defects, chiefly vacancies. The posingon response in these cases has in many instances been exploited to develop definitive conclusions in areas of previous controversy. One such example derives from a body of work spearheaded by the Finnish group under P. Hautojärvi, in which the carbon-vacancy interaction in $\alpha$ iron was extensively investigated. This interaction 
for many years was a major cause of dispute as to the temperature (and stage assignment) of single-vacancy free migration.

In Fig. 10 we show the results of Hautojärvi et al. (1979) for $\alpha$ iron ( $C<5$ appm), electron irradiated at $20 \mathrm{~K}$ and warmed during sample transfer to $77 \mathrm{~K}$. The figure shows the three lifetime measurements for unirradiated, annealed to $180 \mathrm{~K}$, and annealed to $230 \mathrm{~K}$. The $170-\mathrm{psec}$ lifetime for the $180-\mathrm{K}$ anneal corresponds to single-vacancy traps. The growth of the lifetime to $250 \mathrm{psec}$ is conclusive evidence for the presence of vacancy clusters. The authors conclude, therefore, that Stage III at $220 \mathrm{~K} \mathrm{must}$ be due to the long-range migration of single vacancies. This not only nailed down a point of contention, but opened up the new possibility of exploring details of vacancy-carbon interactions in iron using positrons. These interactions have long been of scientific and technological interest.

The basic carbon-vacancy interaction - namely trapping - is shown nicely in Fig. 11 from the work of Vehanen et al. (1982) for electron-irradiated specimens of $\alpha$ iron as above. Two dopant cases are considered (50 and 750 appm C) for identical irradiations. The bottom portion of the curve demonstrates that in annealing through Stage III, four times as many vacancies survive to act as positron traps in the higher $\mathrm{C}$ specimen. This is due to the trapping of the migrating single vacancies by the carbon, and the fact that a vacancy-carbon complex is itself a trap for positrons. The upper part of the figure shows that vacancy clusters are the predominant trap centers above Stage III in the lower-C specimen, demonstrating that clustering is more favorable than trapping at $\mathrm{C}$ in that case. Free-carbon migration at $350 \mathrm{~K}$ is also clearly demonstrated in the bottom portion of the figure. 
Positron studies have been applied to other defect studies in $\alpha$-iron. The first defect that was suggested to act as a trap for positrons is the dislocation (Dekhtyar et al., 1964). In vacancy or void studies, the dislocation density is usually small enough such that its trapping contribution can be neglected. In cold-worked specimens, however, dislocations can be the dominant trap. Also, one should keep in mind the two major types of possible dislocation traps; i.e., edge and screw dislocations. In a study of high-purity $\alpha$ iron Park et al. (1986) used positron spectroscopy, internal friction, TEM, and optical spectroscopy to study the dislocation densitites after deformation. By using pure single crystals and deforming by bending or tension at both room and low temperatures, preferential densities of either edge or screw dislocations could be produced. In this way for the first time a lifetime could be established for each dislocation type. A technique for measuring the dislocation densities for both species simultaneously was then in hand. Figure 12 shows the edge and screw dislocation densities they deduced for a crystal deformed in tension at 200 K. As expected the screw component was larger than the edge component. Of interest is the fact that the total dislocation density as measured by positron spectroscopy was $\sim 10 \%$ higher than the values achieved by traditional etch-pit counting. It is believed that the positron results are the more accurate since they are a true bulk measurement and not subject to the problems of sample preparation and surface effects associated with etch-pit determinations. This improvement, allowing the resolution of two lifetime components in dislocation density measurements, has led to further work. A recent study by Lee et al. (1986) identified various isochronal-annealing recovery stages in cold-rolled $\alpha$ iron by specifying the dislocation type responsible. These types of measurements, coupled with the measured lifetime and Doppler-broadening parameters, are also allowing more accurate machine calculations of electronic distributions along dislocation cores. These same measurement techniques and 
calculations are now being used to quantify trapping characteristics of hydrogen on dislocations.

There are, of course, many more positron-spectroscopy applications to studies of materials than can be covered here. Defect and microstructural studies are the mainstays owing to the defect-positron trapping interaction. The determination of vacancy formation enthalpies in a wide range of metals has been a major advancement. The contributions of positron spectroscopy to the latest hot field, namely oxide superconductivity, are not yet notable. No review these days, however, could be complete without their mention. Jean et al. (1987) showed that dramatic changes in annihilation parameters take place below $T_{c}$ with a discontinuity at $T_{c}$. Recently, Usmar et al. (1988) investigated the behavior of twin boundaries in various compositions of $\mathrm{YBa}_{2} \mathrm{Cu}_{3} \mathrm{O}_{7}$ using positron and TEM techniques. There are also various $2 \mathrm{D}-\mathrm{ACAR}$ studies of the electron momentum distributions for several different high- $T_{c}$ materials presently being conducted, looking for evidence of a Fermi surface. It is still too early, however, to couple these investigations directly to the nature of the superconductivity itself. Clearly, however, the future for new problems in bulk studies for positrons still looks bright. 


\section{POSITRON BEAMS AND NEAR-SURFACE STUDIES}

In adoition to the "bulk" materiais research represented above, there has recently been an accelerated effort in the relatively new "slow positron" technique for studying surface and near-surface phenomena. The production of a positron beam involves the moderation of positrons from a standard $\beta^{+}$emitting radioisotope, and subsequent re-emission of the positrons from the surface of the moderator. This procedure and much of the solid-state research that has been done with positron beams has recently been reviewed by Schultz and Lynn (1988), and will not be discussed further here. The important new features introduced by the use of these tunable sources of positrons are: (i) the variable incident energy means that the positrons can be usied to study depth-dependent properties, (ii) the separation of the source from the target means greater Rexibility in experimental parameters (e.g., sample temperature), and (iii) the availability of very low incident energies allows surface and thin-film studies not possible by conventional methods.

All of the techniques for bulk-solid positron research described in the previous section can (and have been) utilized in positron beam experiments. In addition, low-energy positrons stop near enough to the sample surface that new experimental variables are introduced, illustrated in Fig. 13. As well as the usual annihilation from various bulk states (free or trapped), positrons may diffuse back to the surface where they are either localized in a surface state, or are reemitted as slow positrons or as positronium (Ps). The latter process occurs (by picking up an electron) only at the surface since Ps will not form in most solids, and both the $e^{+}$and Ps re-emission processes generally will not occur unless the solid surface has been cleaned in very good or even ultrahigh vacuum conditions. The surface processes are often the focus of 
detailed study, for example in experiments such as the low energy positron diffraction work of Mayer et al. (1987), positron work-function measurements (e.g., Murray et al., 1980), surface magnetism (Gidley et al., 1982), and many others. In other experiments, $e^{+}$or Ps formation, or trapping in the surface state are measured only as signals that positrons have in fact reached the surface.

The mean depth at which positrons stop in a solid is related to incident positron energy $E$ by

$$
\overline{\mathbf{z}}=\mathrm{AE}^{\mathrm{n}},[2]
$$

where the constant has been empirically determined by Vehanen et al. (1987) to be A 400/ for density $\rho$ in $\left[\mathrm{gm} / \mathrm{cm}^{3}\right], \bar{z}$ in $[\AA], E$ in $[\mathrm{keV}]$ and the power n 1.6. Assuming that the stopping profile of monoenergetic positrons is well described by a Gaussian-derivative function (Valkealahti and Nieminen, 1984), the relationship between energy and the mean positron diffusion length $\mathrm{L}_{+}$is

$$
L_{+}=\sqrt{D_{+}{ }^{T_{\text {eff }}}}=\left(\frac{\mathrm{A}}{1.26}\right) \mathrm{E}_{0}^{\mathrm{n}},[3]
$$

where $E_{0}$ is the energy at which half the positrons return to the surface (i.e., $F_{s}=0.5$ ), $D_{+}$is the positron diffusion constant, and $\tau_{e f r}$ is the effective lifetime of the positron as a freely diffusing particle. The interrelationship between incident energy, mean stopping depth, and bulk $\left(F_{b}\right)$ or surface $\left(F_{s}\right)$ annihilation fractions of positrons for silicon and aluminum lattices (without defects) is represented in Fig. 14.

An example of the use of $E_{0}$ for a particularly difficult problem in materials 
science was a determination by Nielsen et al. (1985) of the vacancy formation enthalpy for niobium. The data shown in Fig. 15 were taken in thermal equilibrium over the range from room temperature up to $2500 \mathrm{~K}$, and the best fit to the data was obtained assuming $\mathrm{H}_{1 \mathrm{v}}^{\mathrm{F}}=3.3 \mathrm{eV}$ (curve b). A previous measurement by Maier et al. (1979) of Doppler-broadening parameters in Nb suggested that the formation enthalpy was in fact much lower $(-2 \mathrm{eV})$, and that thermal detrapping of positrons from the vacancies was important. The data shown in Fig. 15 could not be adequately fit using detrapping or with a formation enthalpy below $\sim 3 \mathrm{eV}$.

During the past decade thin splat-cooled foils, the so-called "metallic glasses", have received considerable attention, particularly because of their high magnetic permeability. Much of the research on metallic glasses has centered on the role of defects on the physical and magnetic properties, and in one study Vehanen et al. (1984) combined bulk ACAR studies with positron diffusion $\left(E_{0}\right)$ measurements. Figure 16 shows an example of data for a $\mathrm{Cu}_{30} \mathrm{Zr}_{70}$ alloy that was cycled in temperature from $A \rightarrow B \rightarrow C \rightarrow D \rightarrow E$ (see figure), followed by a high-temperature anneal. The peak rate of angular correlation data is usually larger for positrons that are localized in defects than for those that are freely diffusing, and the drastic increase in $\hat{\mathrm{N}}$ at $T_{\mathbf{c}}$ is evidence for the formation of new defect phases during the crystallization process. The relative insensitvity of $E_{0}$ to the different localized states is seen in the lower part of the Gigure, where the entire temperature sequence $A$ to $E$ resulted in no change that was not reversible. Both the aiffusion-iength data and the ACAR data (solid triangle) show that partial recovery of the alloy is obtained by heating to temperatures much higher than the $600 \mathrm{~K}$ deduced from $x$-ray data.

The most important defect-related applications of variable-energy positrons are 
those involving nonuniform distributions located near the sample surface, since these cannot be measured using any of the bulk-positron techniques. Included in this category are defects formed at interfaces and in thin films during homo- or hetero-pitaxial growth, recovery of amorphous materials by laser-annealing processes, and radiation-induced defect profiles. The first published example of this type was the work of Triftshäuser and Kögel (1982) for a polycrystalline Ni sample irradiated with various doses of $50-\mathrm{keV}$ He. Although quantitative (depth or concentration) information was not derived from these data, the differences were clearly demonstrated. Trapping of positrons at defects confined to a buried interface was also demonstrated about that time by Schuliz et al. (1983) for an epitaxial layer of $\mathrm{Cu}(111)$ deposited on a $\mathrm{W}(110)$ substrate. In this later case, the recovery of the damaged interface was observed following annealing of the heterostructure above $1225 \mathrm{~K}$.

The first quantitative work on defect profiling in metals with positron beams was presented in a series of publications by the Finnish group (see, e.g., Vehanen et al., 1985; Mäkinen et al., 1986; Bentzon et al., 1987). In cases where one is able to measure the relative back-diffusion fraction of positrons, $J(E) \equiv F_{s}(E) / F_{s}(0)$, for a specimen prior to the introduction of damage (the so-called "reference"), it is possible to define a quantity $K$ that is related to positron trapping,

$$
K(E)=1-\frac{J_{\text {def }}(E)}{J_{\text {ref }}(E)} \cdot[4]
$$

Figure 1 ? shows $\mathrm{K}(\mathrm{E})$ for $\mathrm{Al}(110)$ sputtered with $\mathrm{Ar}^{+}$ions $\left(\approx 10^{17} \mathrm{~cm}^{-2}\right)$ having energies of $0.4,0.8,1.6$, and $3.0 \mathrm{keV}$. The asymptotic limit of $\mathrm{K}(\mathrm{E})$ is related to the mean 
depth $\langle\mathrm{Z}\rangle$ and total concentration $C_{\mathrm{t}}$ of the defects, the specific trapping rate of the defect for positrons $\nu\left(\simeq 5 \times 10^{14} \mathrm{sec}^{-1}\right)$, and the positron diffusion coefficient $D_{+}(\simeq 0.5$ $\left.\mathrm{cm}^{2} / \mathrm{sec}\right)$ by

$$
\mathrm{K}_{\infty}=1-\left(\cosh \sqrt{2<\mathrm{Z}>\nu C_{\mathrm{t}} / \mathrm{D}_{+}}\right)^{-1} \cdot[5]
$$

Figure 18 shows both $\langle\mathrm{Z}\rangle$ and $C_{t}$ as functions of $\mathrm{Ar}^{*}$ ion energy and angle of incidence. For total concentration studies of this type, this is one of the most quantitative of any of the direct measurement techniques, and similar studies have been done by Bentzon et al. (1987) for sputter damage and thermal annealing of a Mo(111) sample.

The technological significance of defects in semiconductors has in recent years resulted in a partial shift of scientific emphasis away from studies of metals. Positron studies are no exception, and there has recently been a tremendous increase in the numbers of traditional bulk experiments (see, e.g., work by Dannefaer et al., 1986/1987, and Dlubek and Krause, 1987), as well as positron-beam studies. One such investigation is the work on damage induced in $\mathrm{C}-\mathrm{Si}$ (crystalline silicon) by $\mathrm{H}$ implantation, that has been presented by Keinonen et al. (1988). Depth profiles of the defect distribution were measured using variable energy positrons, and compared with ${ }^{4} \mathrm{He}^{+}$channeling measurements of the displaced $\mathrm{Si}$ atom depth distribuiions and nuclear resonance broadening studies of the implanted $\mathrm{H}$ distribution. They were able to separate the damage into 3 distinct regions associated with vacancy-type defects, maximum deposited energy, and $\mathrm{H}$ impurities in $\mathrm{C}-\mathrm{Si}$. 
Profiling defects associated with molecular beam epitaxially (MBE) grown $\mathrm{Si} / \mathrm{Si}(100)$ epilayers is the subject of another ongoing study, the first results of which were presented by Schultz, Tandberg et al. (1988). The MBE growth process is itself tested by changing parameters such as dopant type or concentration, substrate temperature, and substrate cleaning procedure. The Doppler-broadening parameter $S(E)$ was measured and subsequently modelled by an iterative solution to the diffusion equation with an assumed profile of defects and electric fields (see Tandberg et al., 1988). An example is shown in figure 19, where curve (a) is obtained for the "reference" substrate maierial (i.e., undefected), and curve (b) is for a $0.3-\mu \mathrm{m}$-thick layer grown several-hundred degrees below the optimum temperature of $\sim 750^{\circ} \mathrm{C}$ on $\mathrm{Si}(100)$. Positron trapping in open-volume defects in curve (b) is clearly evident. The appropriate model (solid curve) involved near-saturation trapping of positrons in a very high concentration $\left(10^{-4}\right.$ to $10^{-3}$ per atom) of vacancy-type defects at the interface, and a lower concentration (approximately one order of magnitude) spread uniformly throughout the overlayer. Annealing of the epilayer system in vacuum at $1000^{\circ} \mathrm{C}$ for $1 \mathrm{~h}$ resilled in the data shown in Fig. 19(c). In this case, the solid line was obtained using a defect concentration in the model which was decreased by about an order of magnitude, and a change in the defect signature (i.e., the $S_{d}$ parameter) to one more appropriate for a vacancy-oxygen complex. Continued work in this area should help to solve some of the uncertainties which are presently introduced by inadequate knowledge of defect signatures, position stopping profiles, and specific trapping rates for positrons. 


\section{CONCLUSIONS}

In conclusion, we have reviewed the basic experimental techniques used for the study of materials by positron annibilation. Quantifative sensitivity has been demonstrated to various defects that include vacancies and vacancy clusters, vacancy-impurity complexes, and amorphized regions of crystalline solids. Studies of this nature, as well as other bulk properties of solids, can be accomplished nondestructively and (often) in situ owing to the very low doses of highly penetrating radiation required. In spite of the maturity of the field, new challenges in bulk materials characterization are constantly arising which are ideally suited to positron spectroscopic techniques. Of particular interest are the various high- $T_{c}$ superconductors which are currently being studied in several positron laboratories world-ride.

In addition to the conventional bulk studies, we have also provided a cursory review of the near-surface and interfacial studies which are being done using variable-energy positron beams. Although relatively unseasoned this technique provides important new capabilities, including various surface spectroscopies, and the ability to depth-profile defects in ion implanted materials and epitaxially grown multilayers. Results were shown for both metallic and semiconductor systems.

The authors would like to acknowledge support of the Natural Sciences and Engineering Research Council of Canada (PJS) and the U.S. Department of Energy under Contract No. DE-AC02-76CH00016 (CLS). 


\section{REFERENCES}

M.D. Bentzon, H. Huomo, A. Vehanen, P. Hautojärvi, and J. Lahtinen: J. Phys. F: Metal Phys., 1987, vol. 17, pp. 1477-1490.

B. Bergersen, E. Pajanne, P. Kubica, M.J. Stott, and C.H. Hodges: Solid State Commun., 1974, vol. 15, pp. 1377-1380.

W. Brandt and A. Dupasquier, eds.: Positron Solid State Physics, Proceedings of the International School of Physics "Enrico Fermi", 1981, course IXXXIII, North-Holland Publ. Co., Amsterdam, 1983.

D.M. Chen: A 2D-ACAR Study of Positron Interactions with Surfaces of Aluminum and Silicon, 1987, Ph.D. dissertation, City College, New York.

S. Dannefaer: Phys. Stat. Sol. A, 1987, vol. 102, pp. 481-492.

S. Dannefaer, P. Mascher, and D. Kerr: Phys. Rev. Lett., 1986, vol. 56, pp. 2195-2198.

I. Ya G. Dekhtyar, D.A. Levine, and V.S. Mikhalenov: DokL Akad. Nauk. SSSR, 1964, D.W. Gidley, A.R. Köymen, and T. Weston Capehart: Phys. Rev. Lett., 1982, vol. 49, pp. $1779-1783$.

H.E. Hansen, S. Linderoth, and K. Petersen: Appl. Phys. A, 1982, vol. 29, pp. 99-103.

P. Hautojärvi, ed.: Positrons in Solids, Topics in Current Physics No. 12, Springer Publ., Berlin, 1979.

P. Hautojärvi, J. Heiniö, M. Manninen, and R. Nieminen: Phil. Mag., 1977, vol. 35, pp. 973-981.

P. Hautojärvi, T. Judin, A. Vehanen, J. Yli-Kauppila, J. Johansson, J. Verdone, and P. Moser: Solid State Comm., 1979, vol. 29, pp. 855-858.

W. Heitler: The Quantum Theory of Radiation, Ind ed., Oxford Publ. Co., London, 1947.

P.C. Jain, R.M. Singru, and K.P. Gopinathan, eds.: Positron Annihilation, Proceedings of the 7th International Conference on Positron Annihilation, New Delhi, 1985, World Scientific Publ. Co., Singapore, 1985.

Y.C. Jean, H. Nakanishi, S.J. Wang, W.N. Hardy, M.E. Hayden, R.F. Kiefle, H.P. Hor, J.Z. Huana, and C.W. Chu: Phys. Rev. B (Rapid Comm.), 1987, vol. 36, pp. 3994-3996.

P. Jena, A.K. Gupta, and K.S. Singwi: Solid State Comm., 1977, vol. 21, pp. 293-296.

J. Keinonen, M. Hautala, E. Raushala, V. Karttunen, A. Kuronen, J. Räisānen, J. Lahtinen, A. Vehanen, E. Punkka, and P. Hautojärvi: Phys. Rev. B, 1988, vol. 37, pp. $8269-8275$. 
Jong-Lam Lee, James T. Waber, Yong-Ki Park, and J.T.M. DeBlosson: Matls. Science and Eng., 1986, vol. 81, pp. 379-390.

K. Maier, M. Peo, B. Saile, H.E. Schaefer, and A. Seeger: Phil. Mag. A, 1979, vol. 40, pp. 701-728.

G.R. Massoumi, Peter J. Schultz, W.N. Lennard, and J. Ociepa: Nuch Instrum. Meth. $B, 1988$, vol. 30, pp. 592-597.

R. Mayer, Chun-Si Zhang, K.G. Lynn, W.E. Frieze, F. Jona, and P.M. Marcus: Phys. Rev. B, 1987, vol. 35, pp. 3102-3110.

J. Mäkinen, A. Vehanen, P. Hautojärvi, H. Euomo, J. Lahtinen, R.M. Nieminen, and S. Valkealahti: Surf. Sci., 1986, vol. 175, pp. 385-414.

Cherry A. Murray, Allen P. Mills, Jr., and J.E. Rowe: Surf. Sci., 1980, vol. 100, pp. $647-664$.

B. Nielsen, K.G. Lynn, J. Hurst, A. Vehanen, and P.J. Schultz, p. 464 in Jain et al., 1985.

Yong-Ki Park, James T. Waber, Michael Meshii, C.L. Snead, Jr., and C.G. Park: Phys. Rev. B, 1986, vol. 34, pp. 823-836.

M.J. Puska and R.M. Nieminen: J. Phys. F. Metal Phys., 1983, vol. 13, pp. 333-346.

Peter J. Schultz and K.G. Lynn: Rev. Mod. Phys., 1988, vol. 60, pp. 701-779.

Peter J. Schultz, K.G. Lyan, W.E. Frieze, and A. Vehanen: Phys. Rev. B, 1983, vol. 27, pp. $6626-6634$.

Peter J. Schultz, E. Tandberg, K.G. Lynn, B. Nieisen, T.E. Jackman, M.W. Denhoff, and G.C. Aers: Phys. Rev. Lett., 1988, vol. 61, pp. 187-190.

C.L. Snead, Jr. and A.N. Goland: Phys. Letters, 1975, yol. 55A, pp. 189-190.

C.I. Snead, Jr., A.N. Goland, and F.W. Wiffen: J. Nucl. Mat., 1977, vol. 64, pp. 195-205.

C.I. Snead, Jr., K.G. Lynn, Y. Jean, F.W. Wiffen, and P.J. Schultz: Advanced Techniques for Characterizing Microstructures, The Metal"urgical Society of AIME, ed. by F.W. Wiffen and J.A. Spitznagel, 1982, pp. 443-459.

Erik Tandberg, Peter J. Schultz, Geof C. Aers, and T.E. Jackman: Can. J. Phys., 1988 , submitted for publication.

N. Thrane and J.H. Evans: Appl. Phys., 1977, vol. 12, pp. 183-185.

W. Triftshäuser and G. Kögel: Phys. Rev. Lett., 1982, vol. 48, pp. 1741-1744. 
S.G. Usmar, K.G. Lynn, A.R. Moodenbaugh, M. Suenaga, and R.L. Sabatini: Phys. Rev. B (Rapid Comm.), 1988, vol. 38, pp. 5126-5129.

S. Valkealahti, and R.M. Nieminen: Appl Phys. A, 1984, vol. 35, pp. 51-59.

A. Vehanen, K.G. Lynn, Peter J. Schultz, E. Cartier, H.-J. Güntherodt, and D.M. Parkin: Phys. Rev. B, 1984, vol. 29, pp. 2371-2381.

A. Vehanen, P. Hautojarvi, J. Johansson, J. Yli-Kauppila, and P. Moser: Phys. Rev. $B, 1982$, vol. 25 , pp. $762-780$.

A. Vehanen, J. Mäkinen, P. Hautojärvi, H. Huomo, J. Lahtinen, R.M. Nieminen and S. Valkealahti: Phys. Rev, B, 1985, vol. 32, pp. 7561-7563.

A. Vehanen, K. Saarinen, P. Hautojärvi, and H. Huomo: Phys. Rev. B, 1987, vol. 35, pp. $4606-4610$. 


\section{FIGURE CAPTIONS}

Figure 1: Positron wave function in a icc Ni lattice. The left-hand figure is for a delocalized positron in a perfect lattice, and the right-hand figure is for a positron localized in a vacancy (from Puska and Nieminen, 1989).

Figure a. The three most common experimental positron techniques for measuring (a) and (b) electzon momentum, and (c) positron lifetime. When positrons trap in defects there is a reduced overlap with energetic core electrons, leading to narrowing of the momentum (a) or $\gamma$ ray (b) spectra, and to a longer lifetime (c).

Figure 3: Typical experimental system for measuring annihilation $\gamma$ rays. The lineshape parameter most commonly used is " $\mathrm{S}$ ", defined in the figure.

Figure 4: Positron lifetimes in small voids for $\mathrm{Al}$ and Mo as a function of the void radius R. $\mathrm{N}$ is the number of racancies in the yoid. (From Hautogarvi et al, 1977).

Figure 5: The lifetimes of positrons trapped in voids in Mo as a function of annealing temperature following irradiation. The increasing lifetime denotes an increasing void volume. The number of vacancies in the voids is obtained from Eldrup et al., 1976. (From Hautojärvi et al., 1977).

Figure 6: Annealing of Mo following ambient-temperature electron and neutron irradiations. (From Thrane and Evans, 1977). 
Figure 7: The intensity of the component due to positions trapped at voids in Mo and Mo-0.5 at.\% $\mathrm{Ti}$ versus irradiation temperature. Irradiations ware each to $\sim 10$ displacements per atom. (From Snead et al, 1982).

Figure 8: The Doppler-broadening shape parameter $S$ is plotted as a function or irradiation temperature for neutron-irradiated Mo (open circles). The solid line is drawn through the data as a guide only. Scatter in the data taken for the same irradiation temperature is an indication of the uncertainty in the points. The void volume as determined from TEM (triangles) is also plotted as a function of irradiation temperature for comparison. The estimated error in the TEM values is $\pm 30-50 \%$ of the value itself. (From Snead et al., 1982).

Figure 9: Annealing of Al following 0.6 at.\% He injected at room temperature. The curve shows increasing lifetime as the size of the defects (bubble formation) increases. Open data points are for annealed but unirradiated specimens (From Snead et al, 1977).

Figure 10: Positron lifetime spectra after source-background subtractions in electron-irradiated high-purity $\alpha$ iron at various stages of isochronal annealing. The dramatic change in the lifetime spectrum after $230 \mathrm{~K}$ annealing due to vacancy clustering is easily visible. (From Hautojarvi et al, 1979).

Figure 11: Concentration of monovacancies $c_{v}$ (below $220 \mathrm{~K}$ ), carbon-vacancy pair concentration $c_{c v}$ (above $220 \mathrm{~K}$ ), and effective concentration $c_{c l}^{*}$ of vacancies, which have been absorbed by vacancy agglomerates as a function of the isochronal annealing temperature in electron-irradiated iron-carbon samples. (From Vehanen et al., 1982). 
Figure 12: Dislocation density in an iron single crystal which was deformed in tension at $200 \mathrm{~K}$. Solid circles represents the total dislocation density as measured by positron annihilation and open circles are the values from the etch-pit measurements. Triangles and squares represent the edge and the screw components measured with positron annihilation. (From Park et al., 1986).

Figure 19: A limited view of some of the processes which are important for a monoenergetic positron beam incident on a solid surface.

Figure 14: Fraction of incident positrons that annibilate in the bulk $\left(\mathrm{F}_{\mathrm{b}}\right)$ or at the surface $\left(F_{\mathrm{s}}\right)$ of silicon (solid) and aluminum (dashed) crystals, as a function of incident positron energy. Mean stopping depth, $\bar{z}$, is also shown for each case. (From Chen, 1987 .

Figure 15: Positron diffusion parameter $\mathrm{E}_{0}$ as a function of temperature for a $\mathrm{Nb}(110)$ single crystal. The curves shown are calculated assuming vacancy formation enthalpies of (a) no trapping, (b) $3.3 \mathrm{eV}$, (c) $3.0 \mathrm{eV}$, and (d) $2.6 \mathrm{eV}$. (From Nielsen et al., 1985).

Figure 16: Upper part: The peak counting rate $\dot{N}$ for heat treatment $A$ to $E$ for the metallic glass $\mathrm{Cu}_{30} \mathrm{Z}_{70}$. The full triangle is $\dot{\mathrm{N}}$ measured at room temperature following a $1 \mathrm{~h}$ anneal at $1200 \mathrm{~K}$. Lower part: The positron diffusion parameter $E_{0}$ versus temperature measured in situ during the same heat treatment. The increase of $\dot{N}$ at the crystallization temperature $T_{c}$ indicates the formation of a new defect phase, which is not observed in $\mathrm{E}_{0}$ due to the saturation trapping of positrons. (From Vehanen et al, 1981). 
Figure 17: Experimentally measured positron trapping fractions $K$ as a function of incident positron energy $\mathrm{E}$ and $\mathrm{Ar}^{+}$ion energy for an $\mathrm{Al}(110)$ single crystal. The $\mathrm{Ar}^{+}$ fluence was in each case $\simeq 10^{17} \mathrm{~cm}^{-2}$ and the incident angle was $\theta=75^{\circ}$ away from the normal. (From Vehanen et al, 1985).

Figure 18: Total number of defects per unit area $C_{\mathrm{t}}$ and the mean defect depth $\langle\mathrm{Z}\rangle$ versus $\mathrm{Ar}^{+}$ion energy and angle of incidence. These data are deduced from the asymptotic limit of curves like those shown in Figure 17, using equation [5]. (From Mäkinen et ai., 1986).

Figure 19: Doppler broadening S-parameter versus incident positron energy. The three data sets are (a) "Czrochalski"-grown Si(100) substrate material, (b) $0.3 \mu \mathrm{m}$ MBE-grown (heavily defected) layer on $\mathrm{Si}(100)$, and (c) the same sample as (b) after a $1000^{\circ} \mathrm{C}$ vacuum anneal. Other results from this same study were reported by Schultz, Tandberg et al., 1988. 

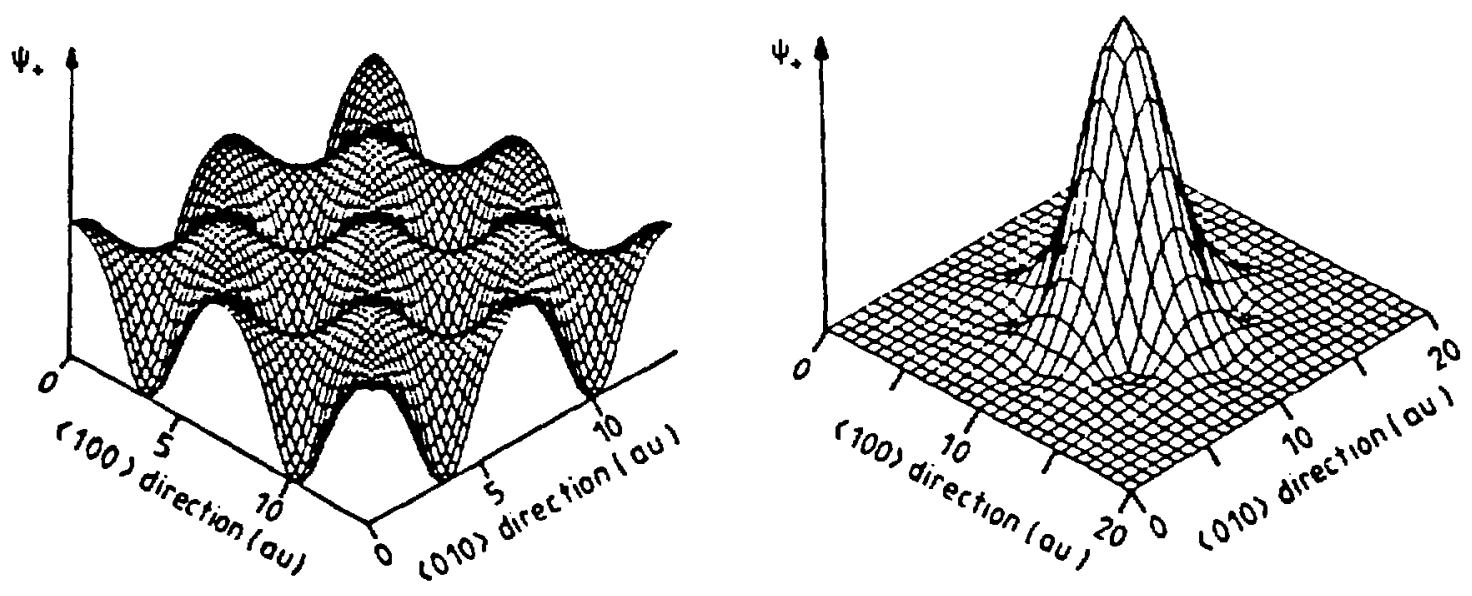
(a) ANGULAR CORRELATION OF ANNIHILATION RADIATION

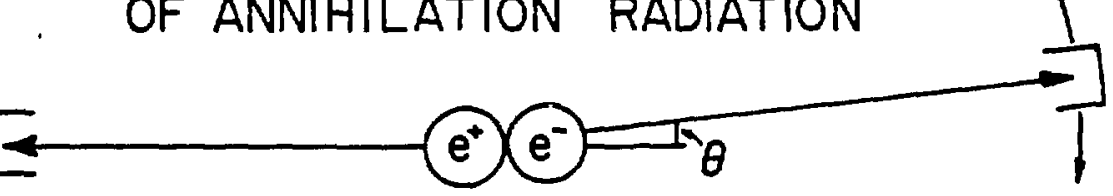

(b) DOPPLER BROADENING

(c) LIFETIME

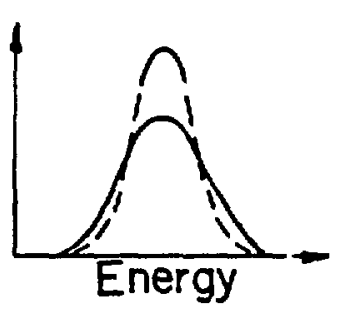

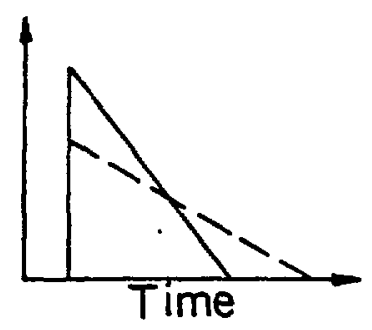

- - Trapped positrons

- Delocalized 
*

Source

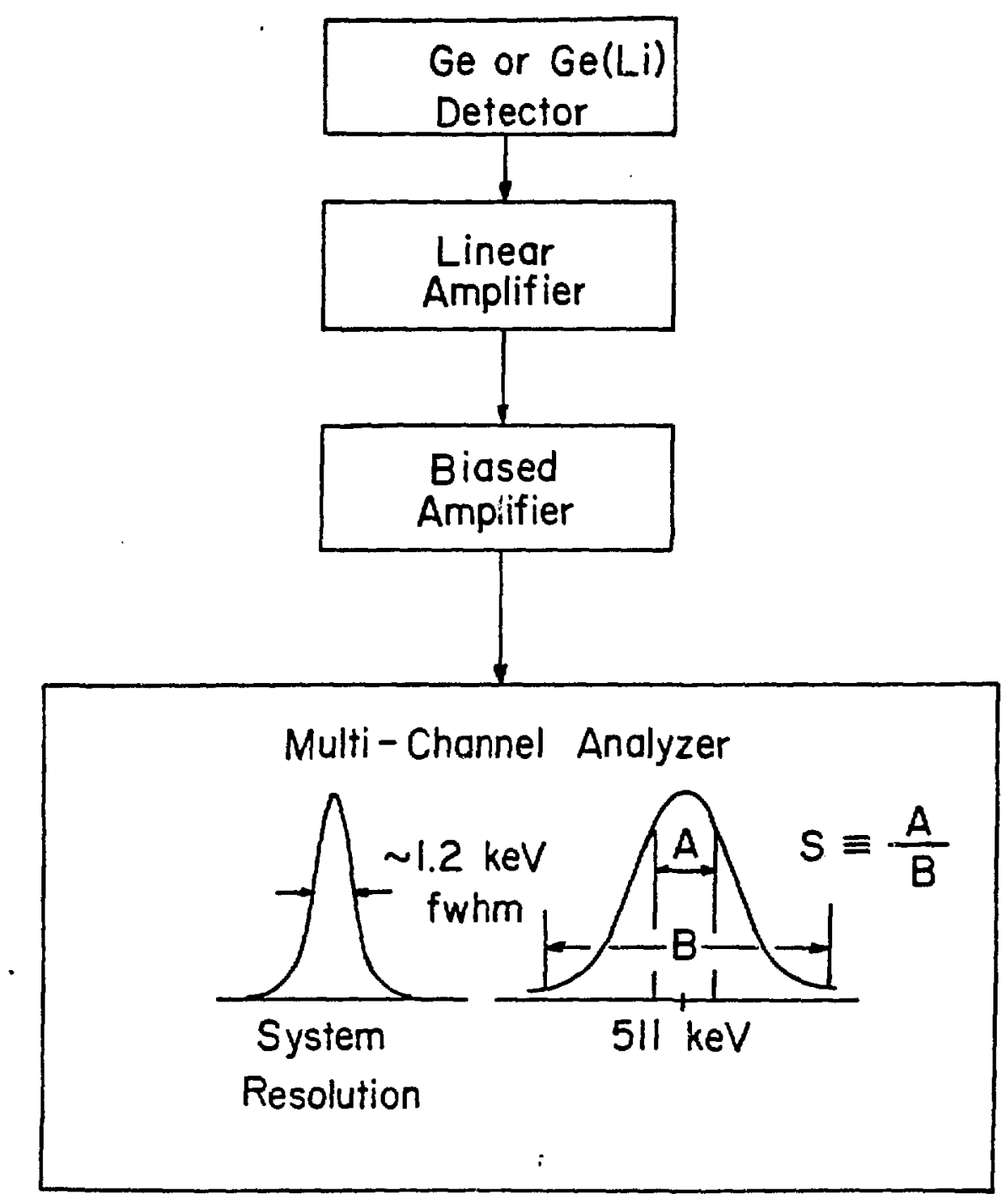

FIG. 3 


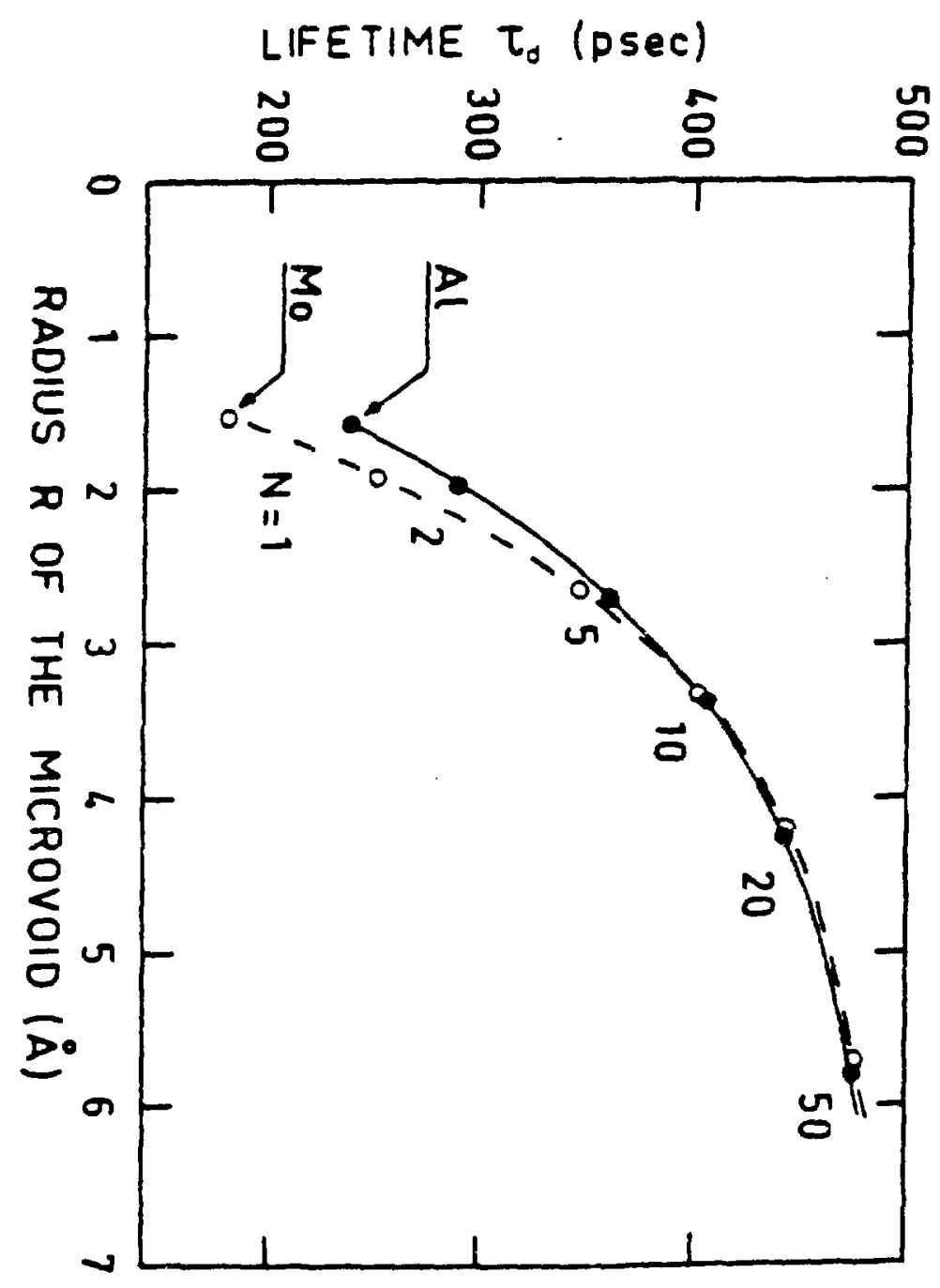

Fig.4 


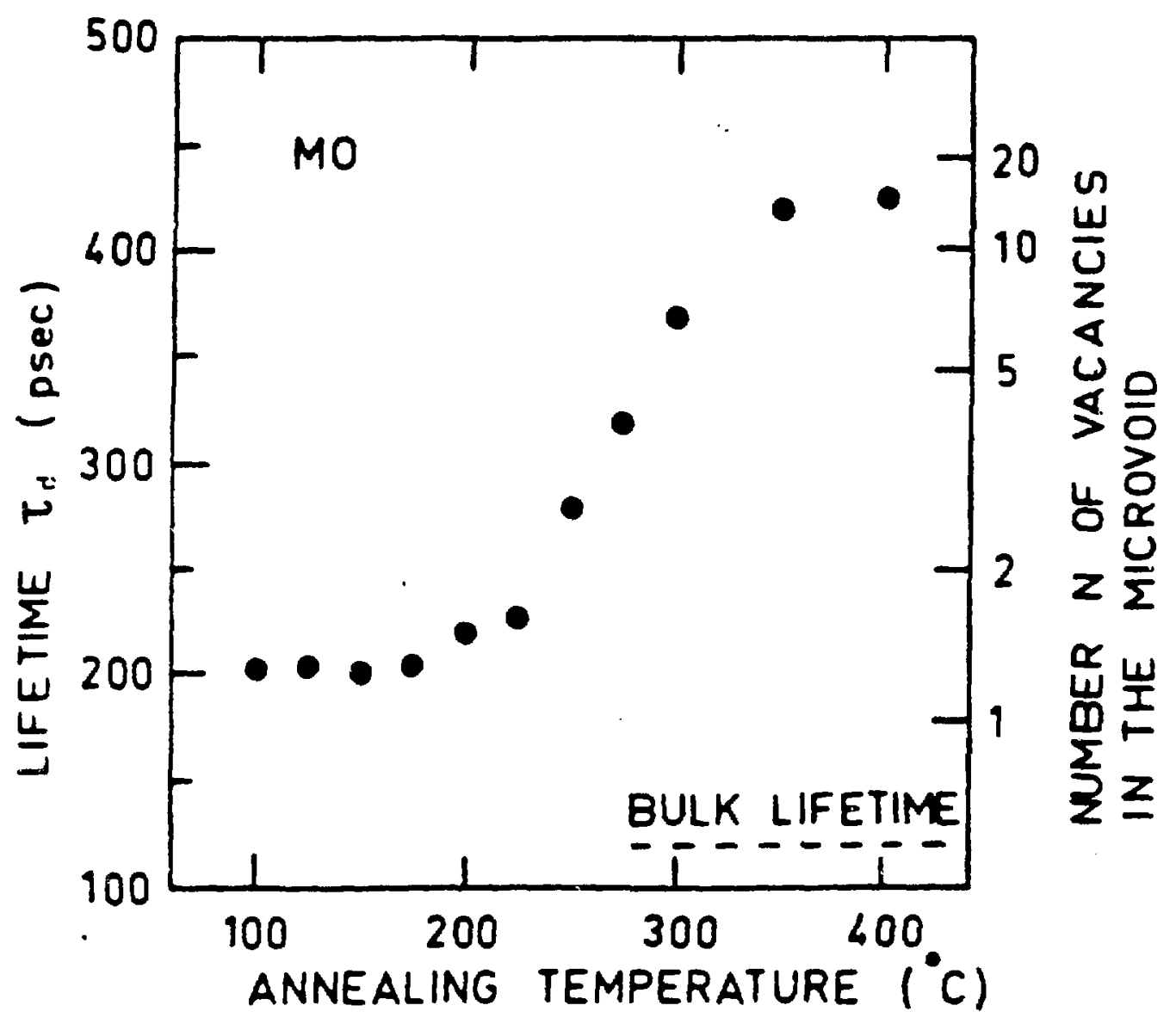

Fine 


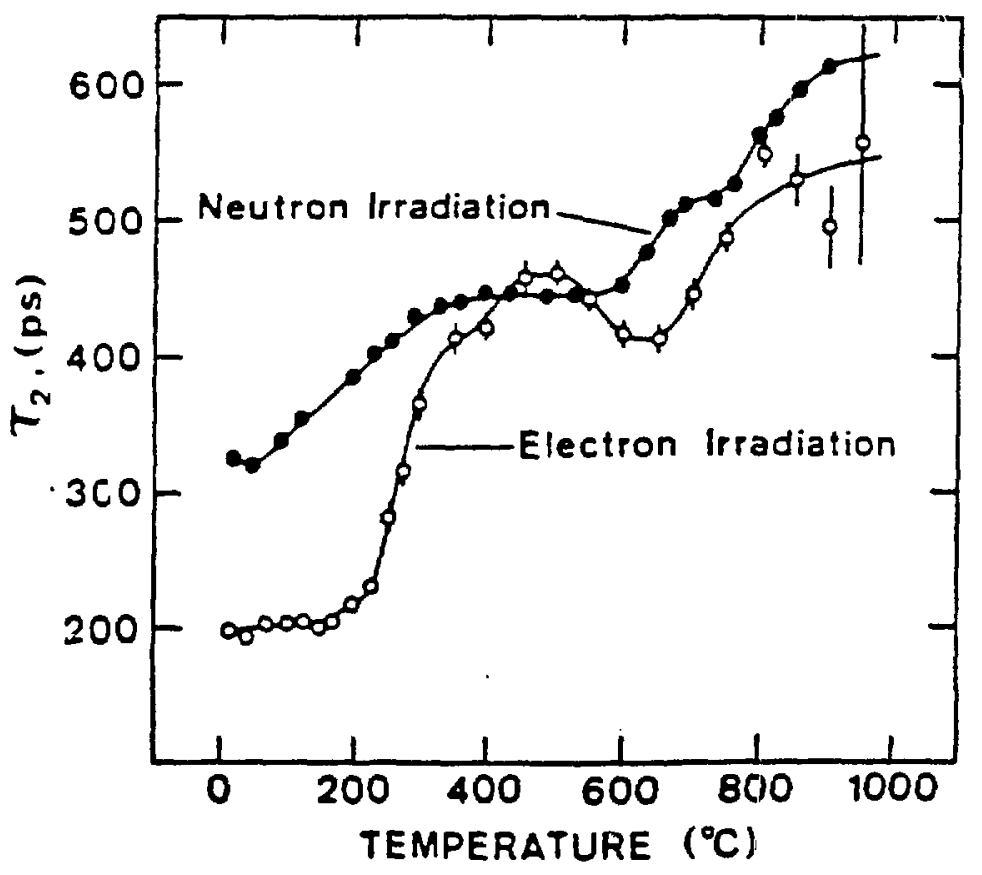

FIG. 6 


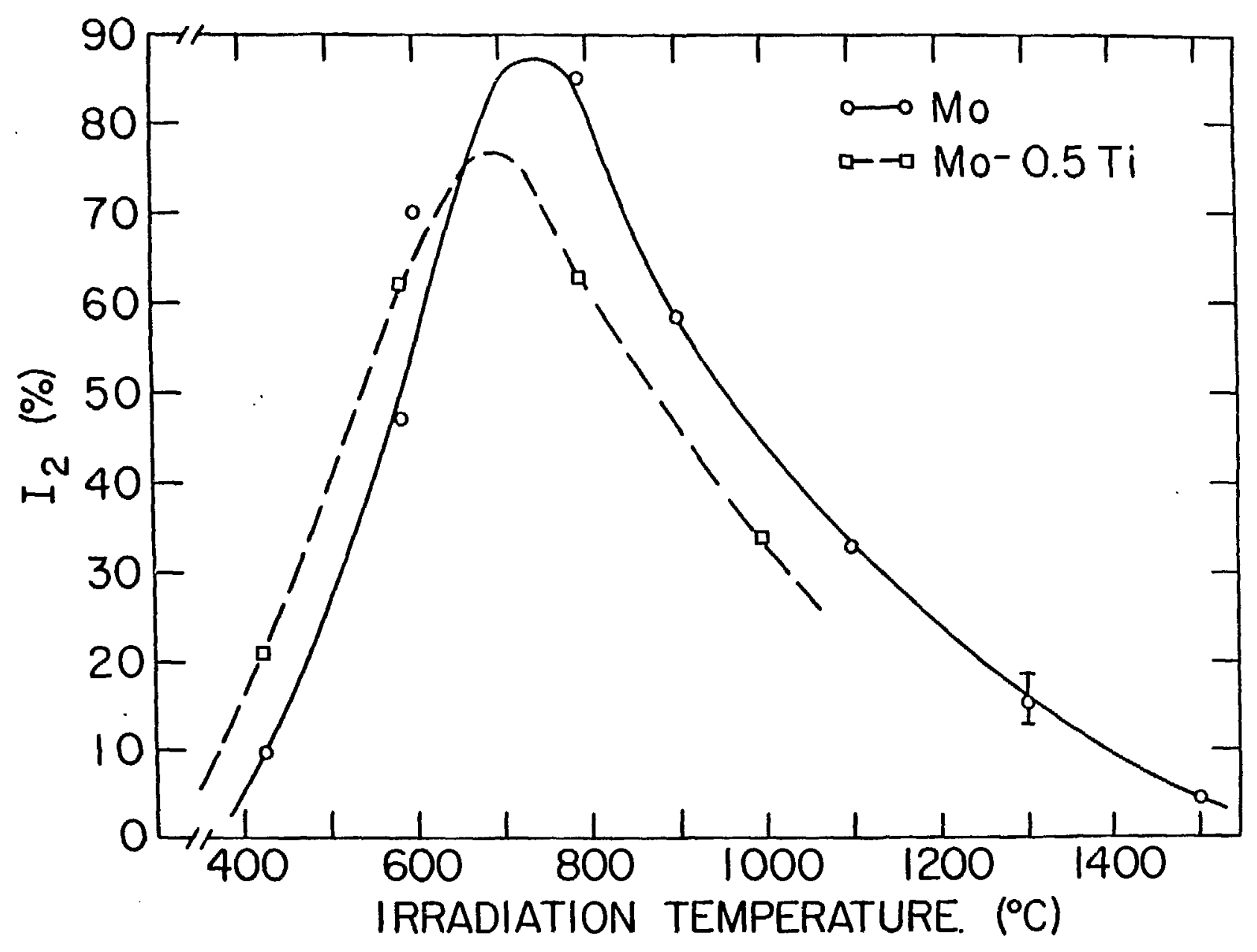




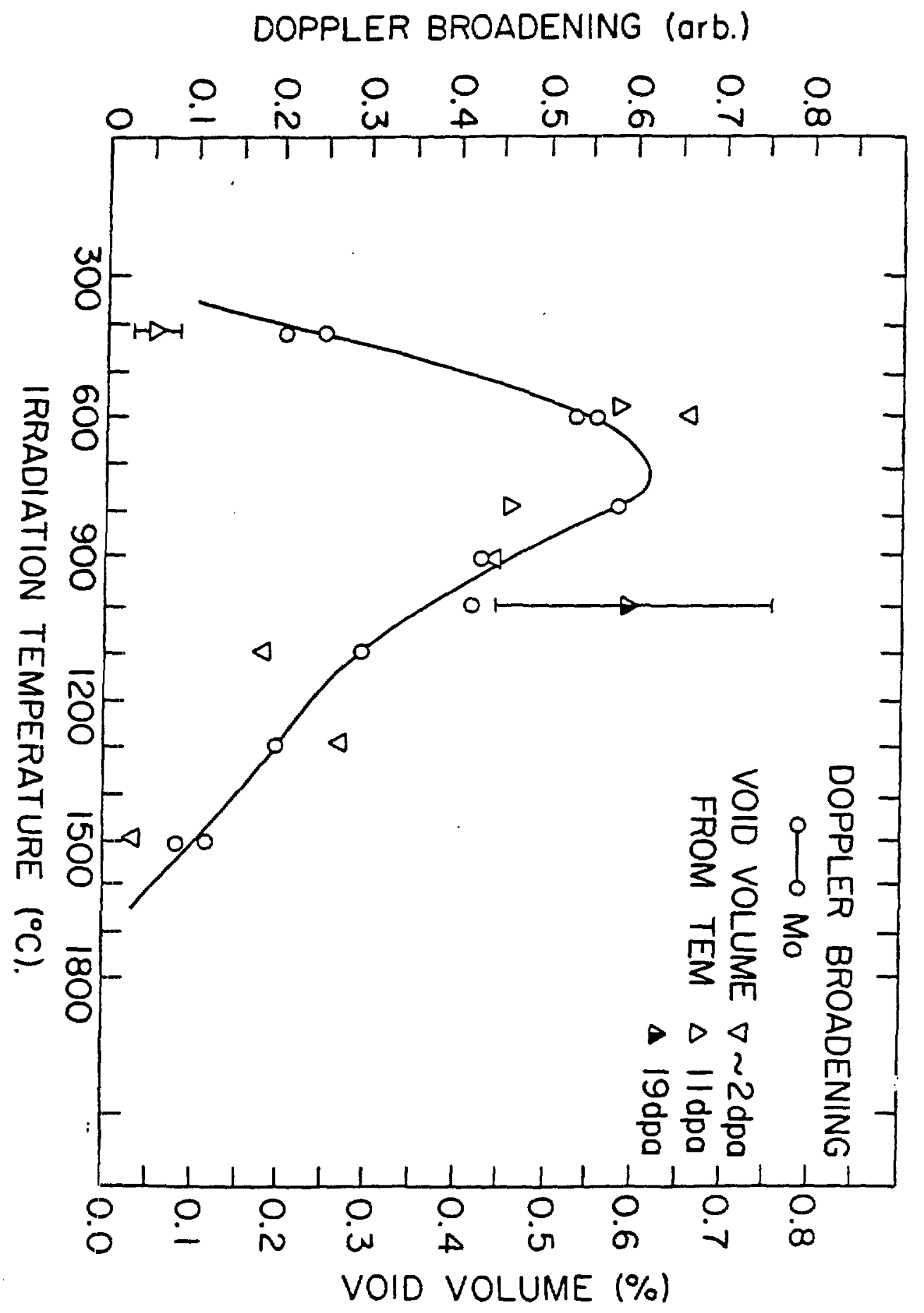

Fis 8. 


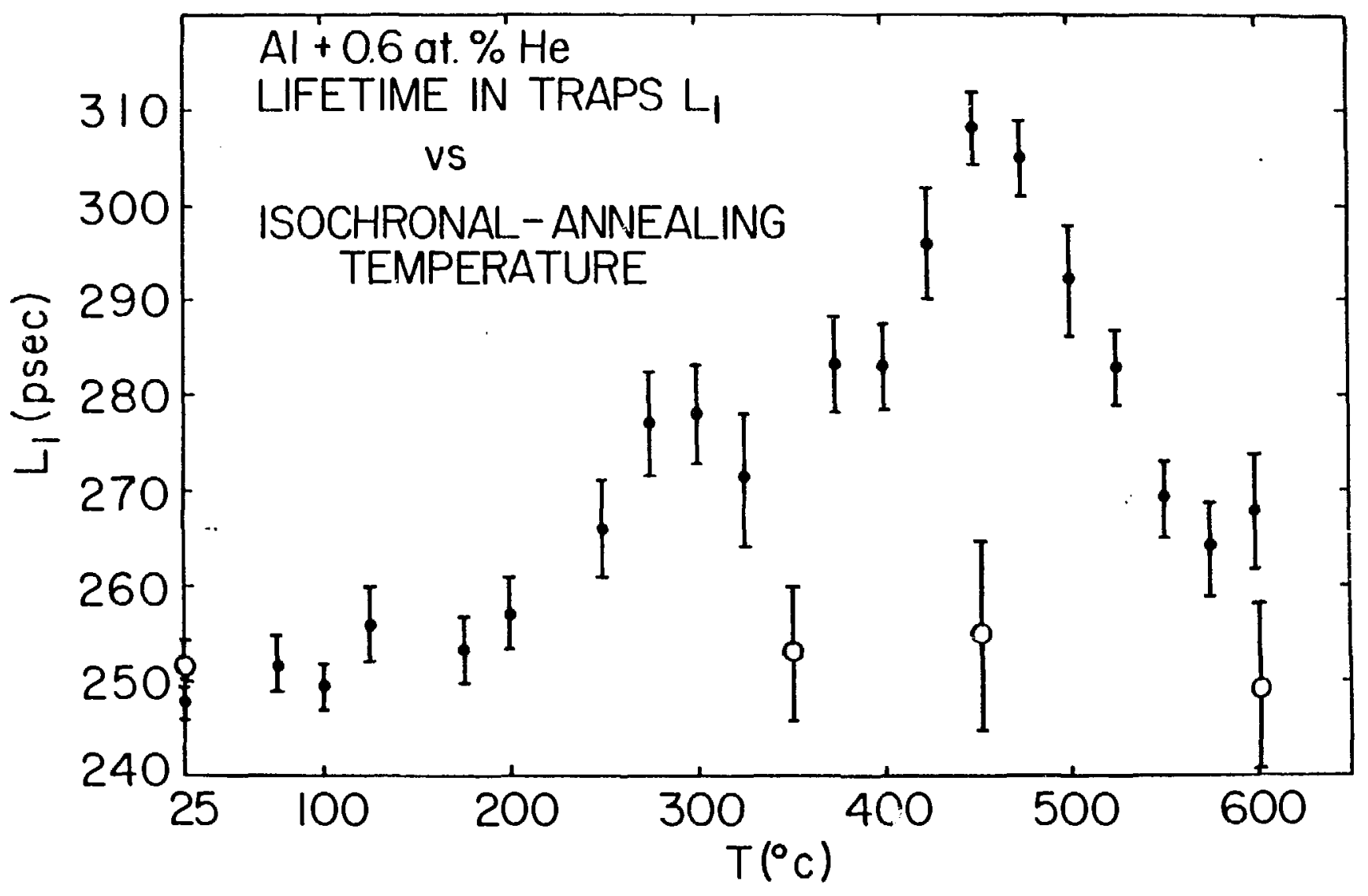




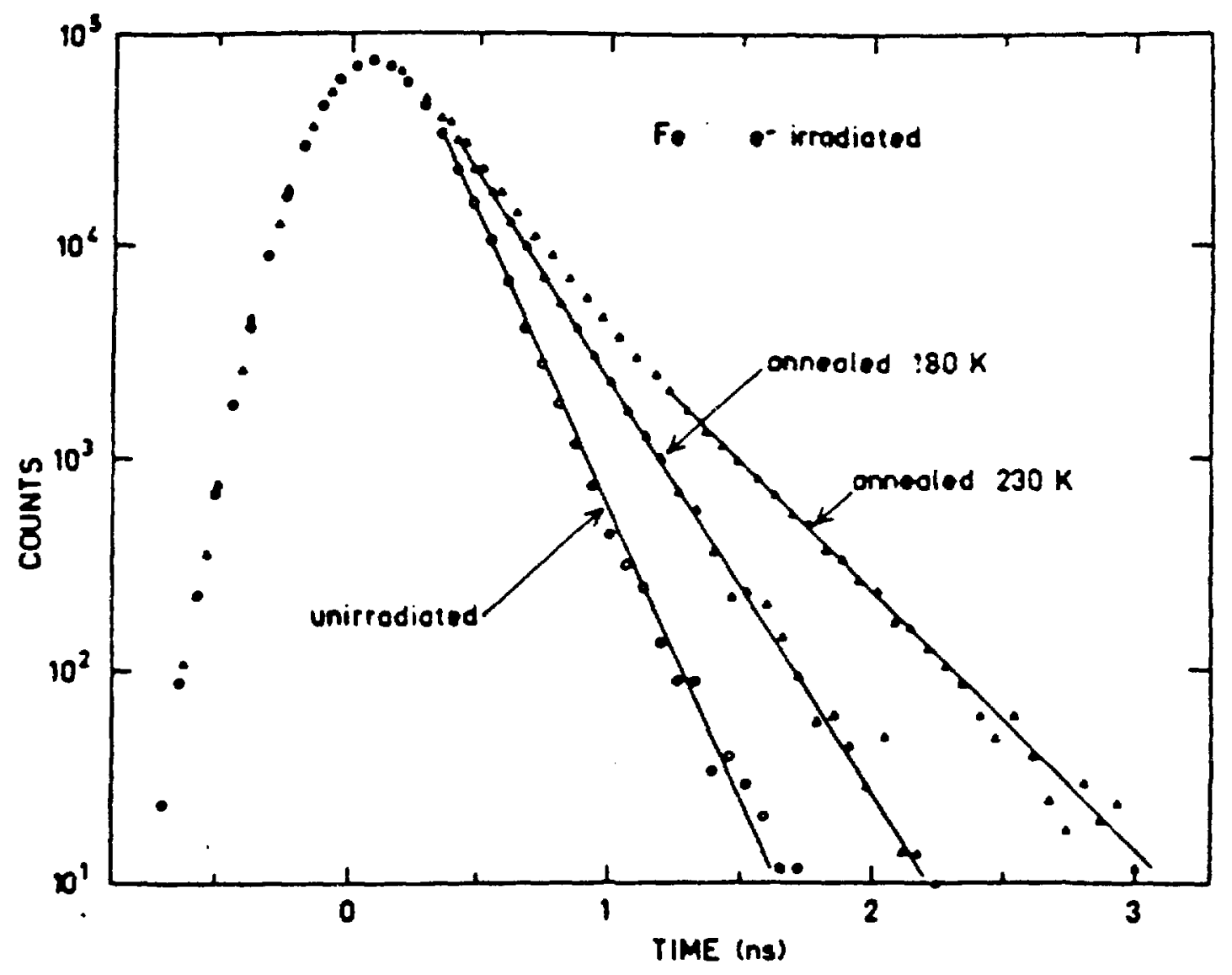

$F / 4.10$ 


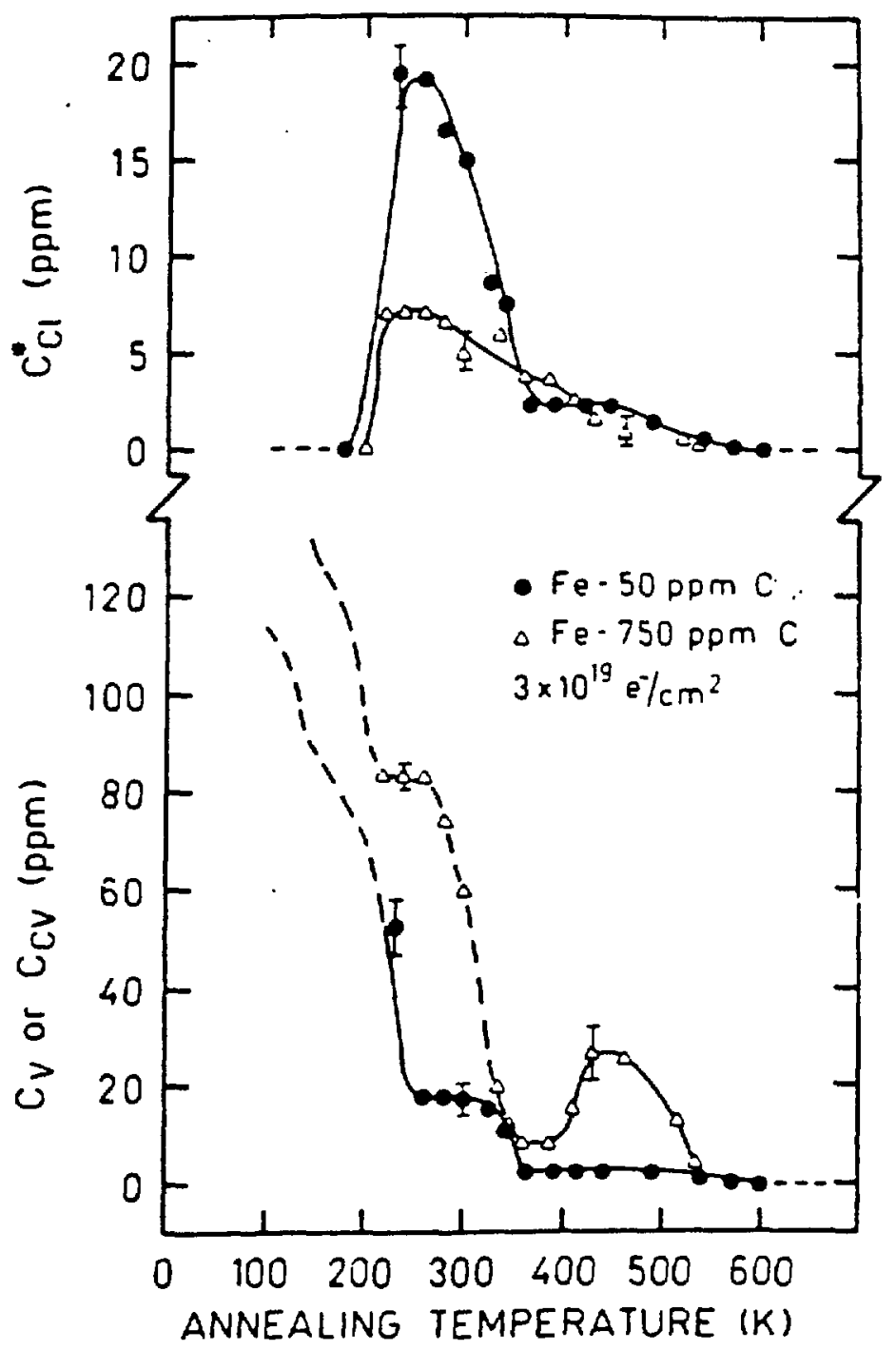

$F / G, I I$ 
Dislocation Density $\left(10^{13} / \mathrm{m}^{2}\right)$

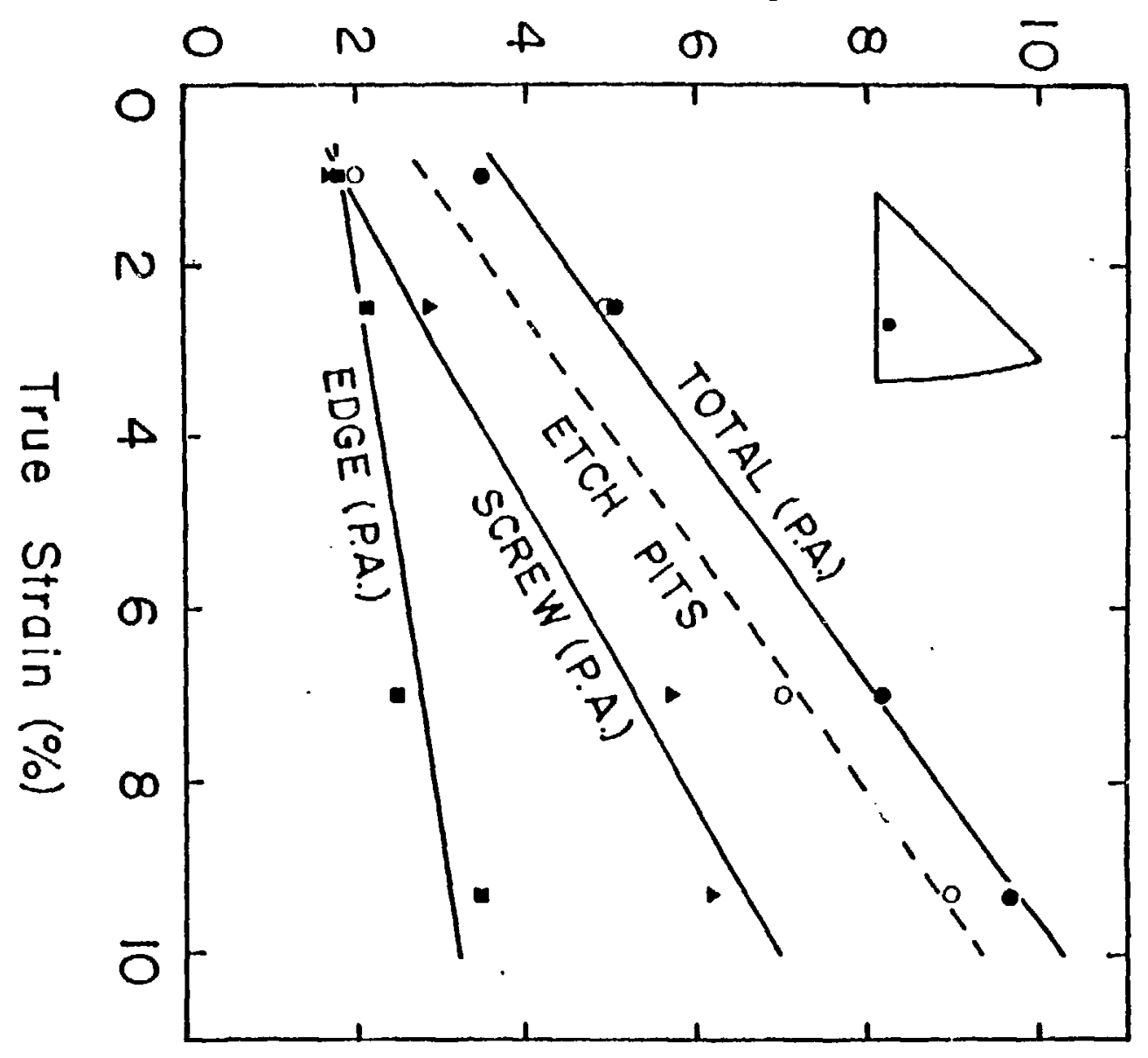




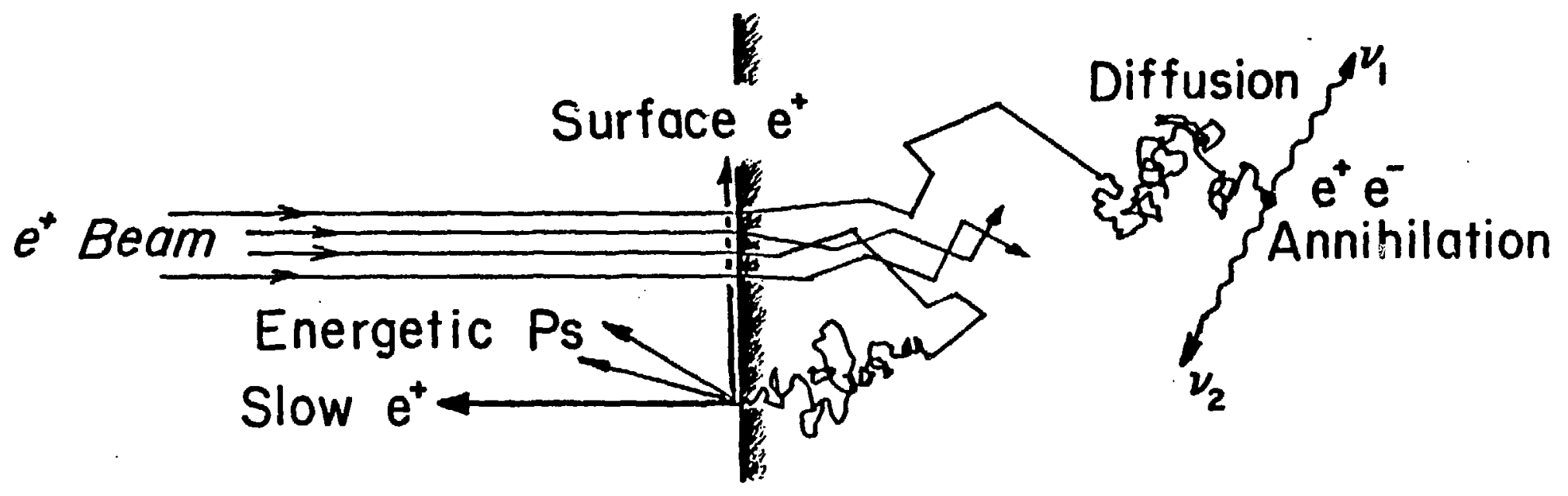




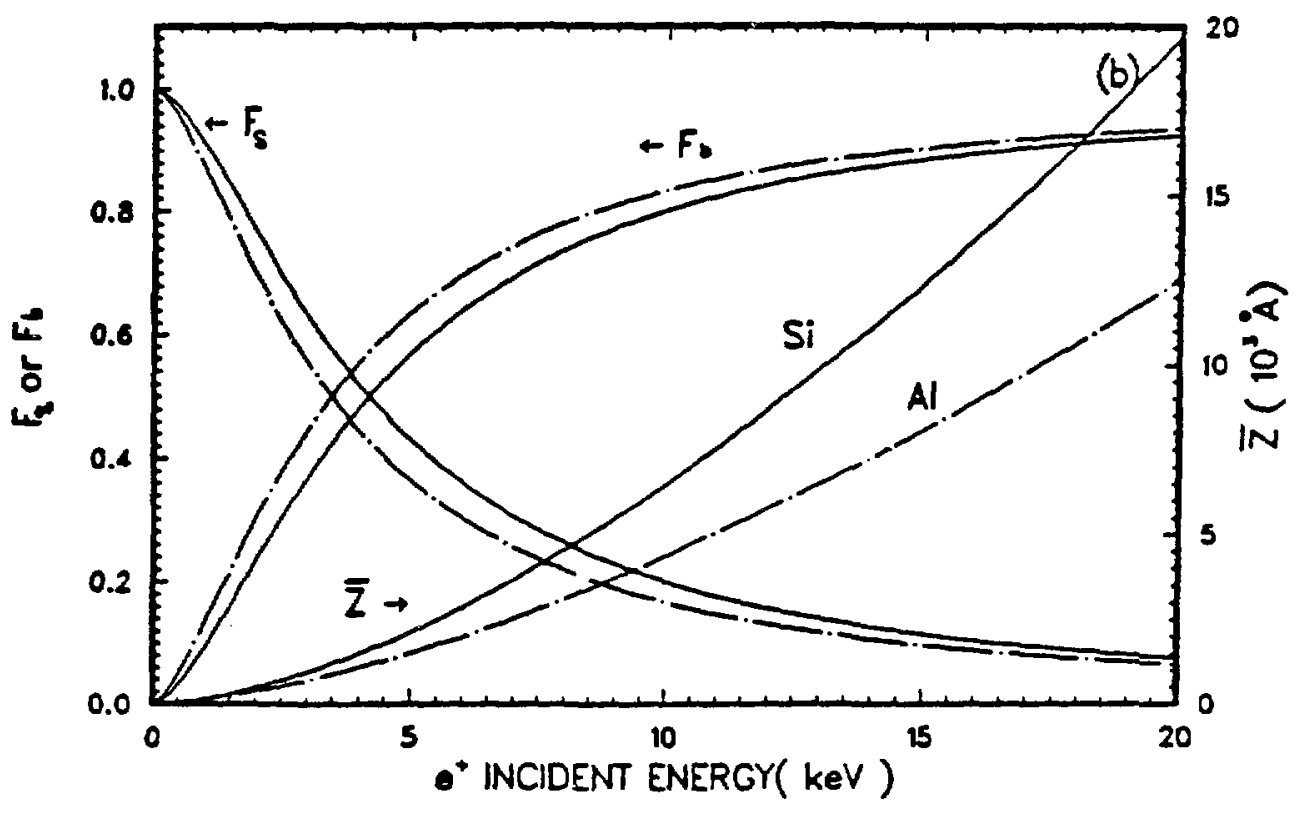

Fla.14 


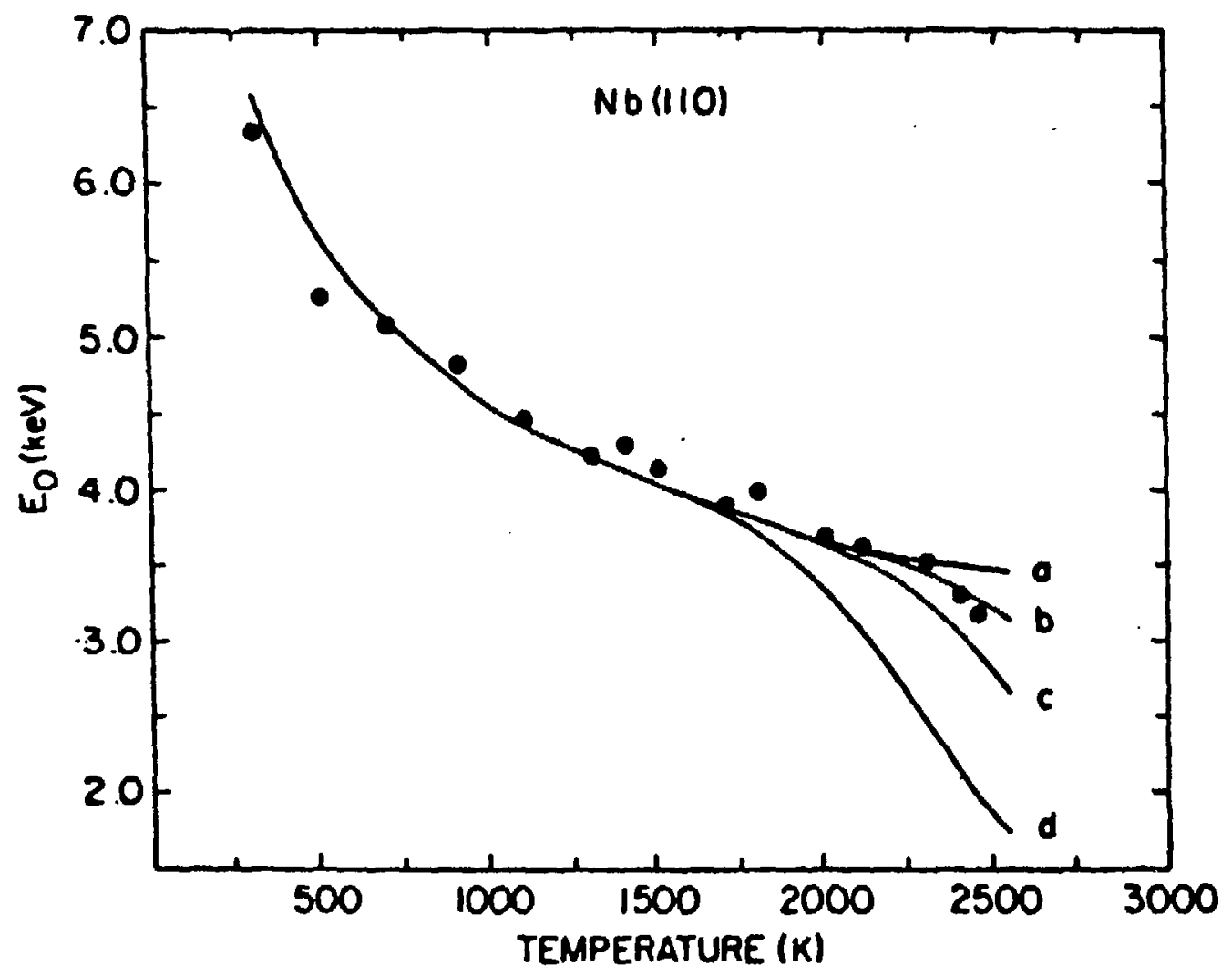




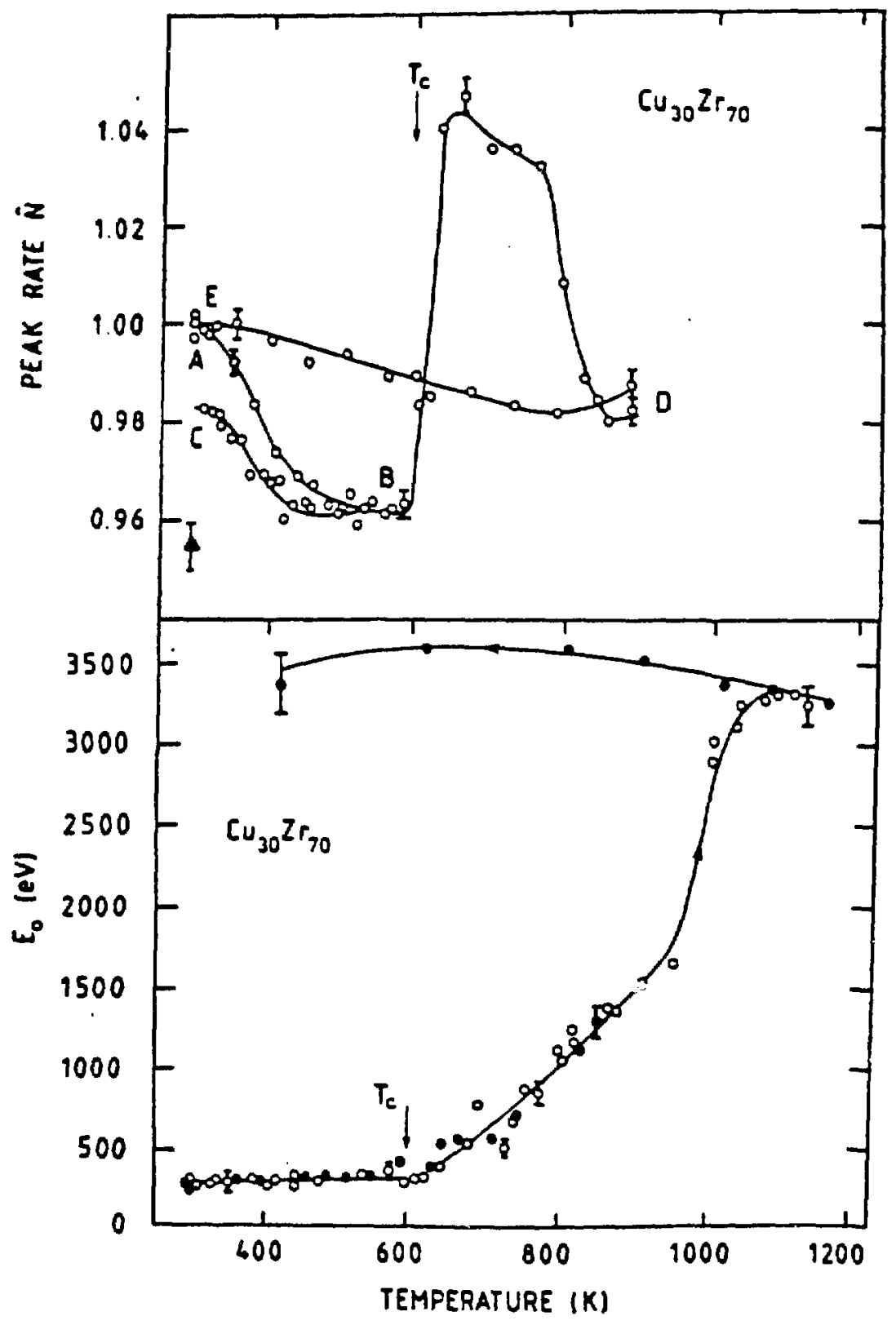

$F 1 G \cdot 16$ 


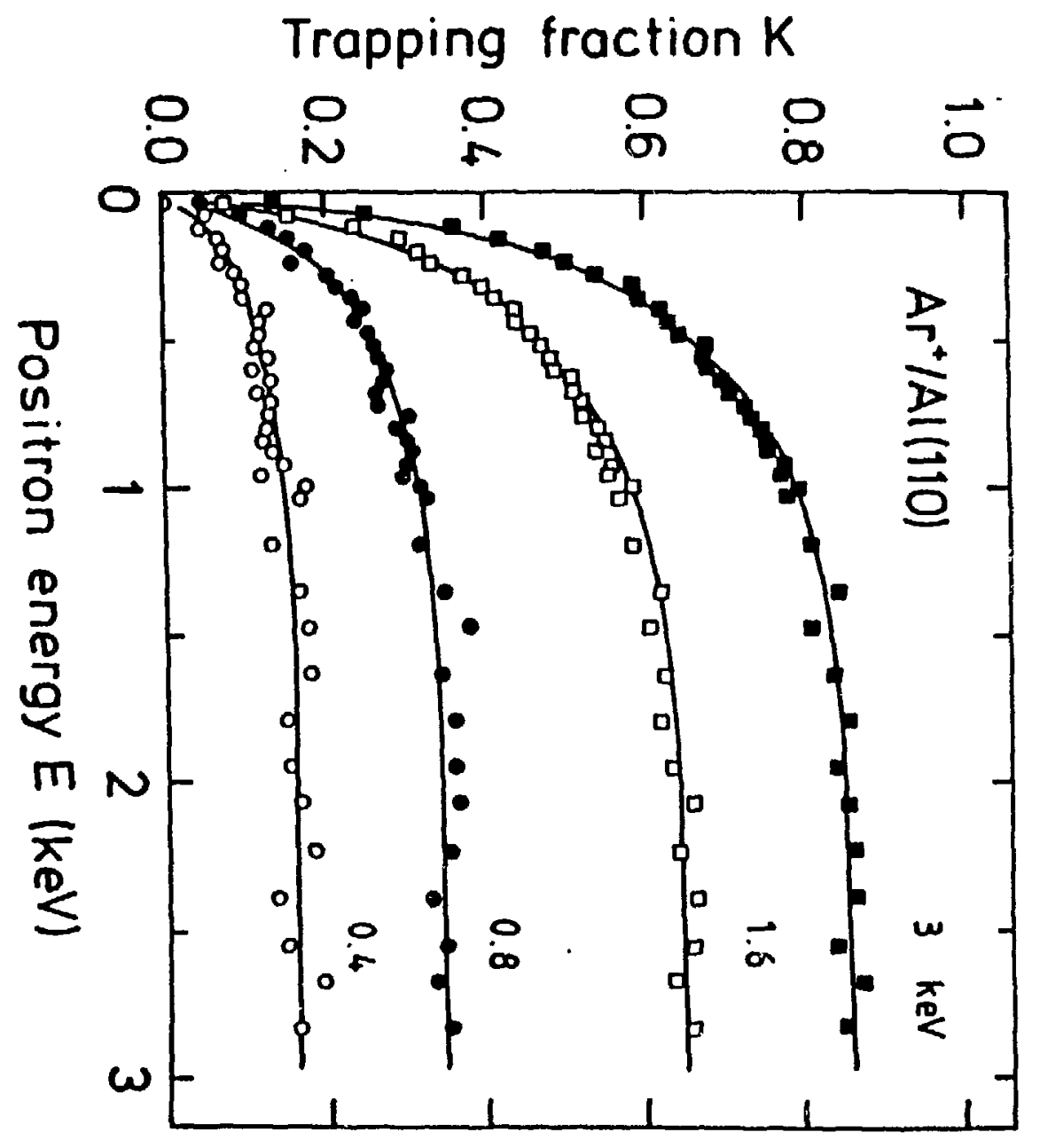




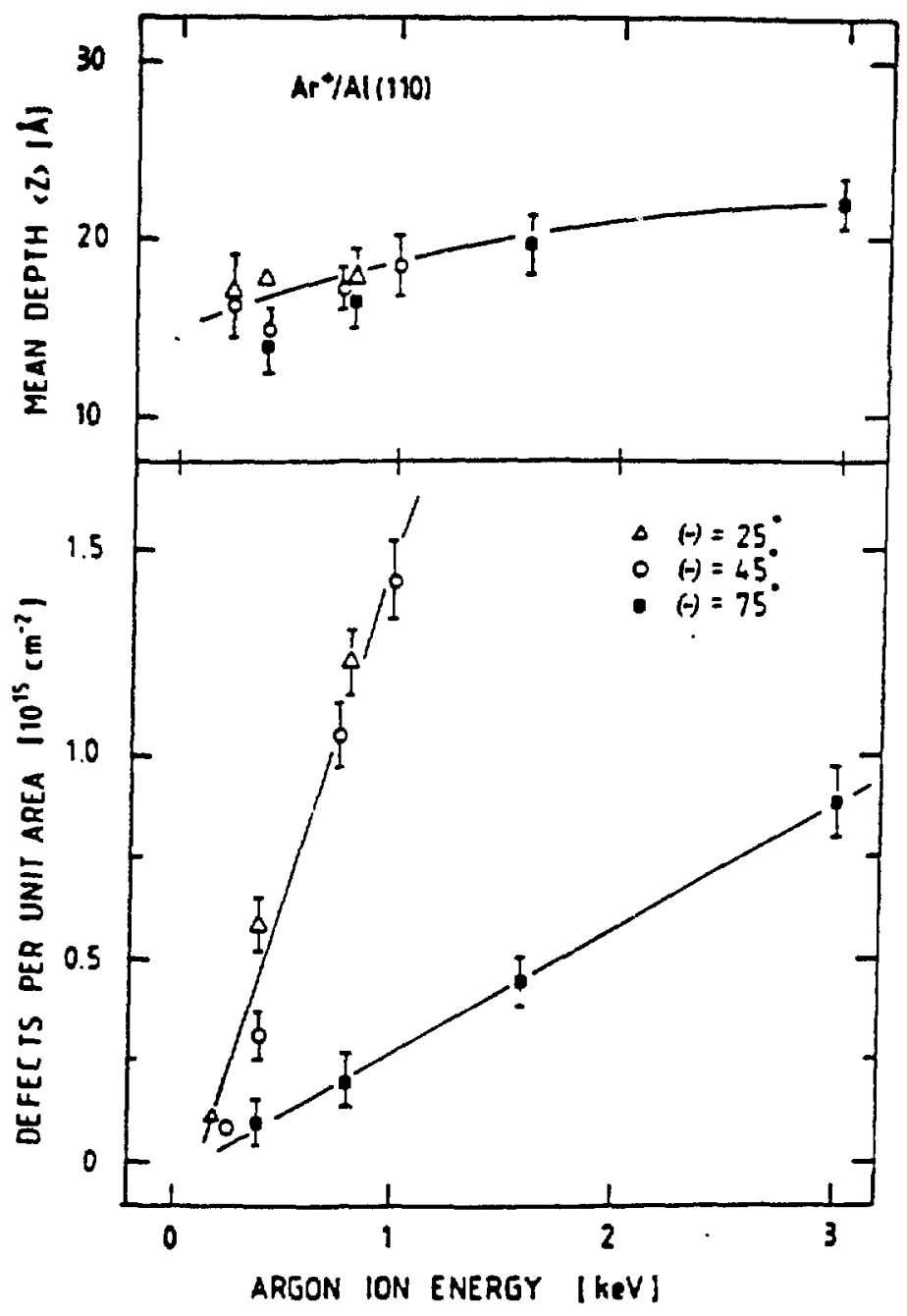

$F(G .18$ 


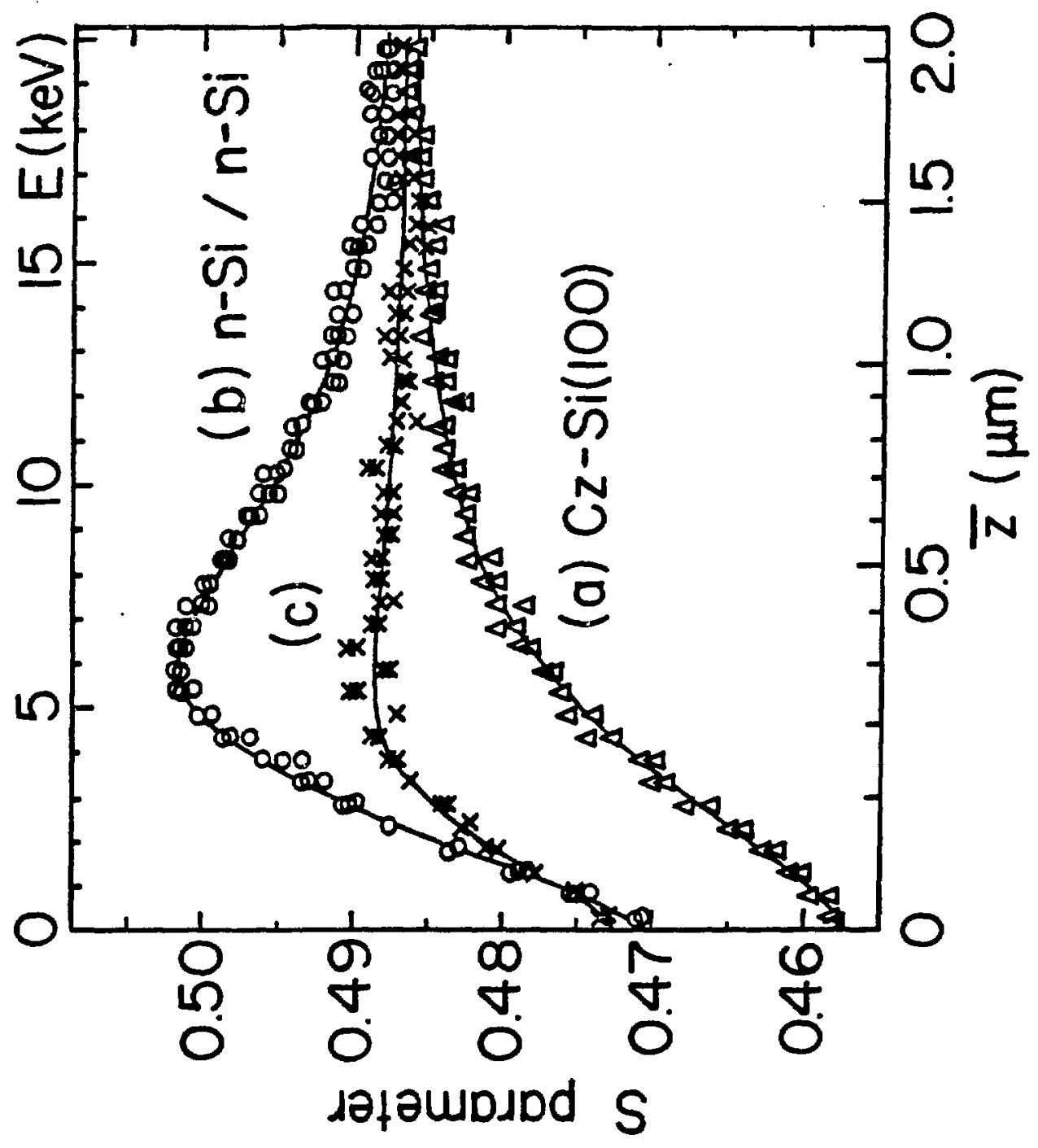

FIG.19 